\title{
Prêcher sur les reliques de la Passion à l'époque de saint Louis
}

Dans son recueil de documents pour servir à l'étude des translations de reliques de 1'Orient vers 1'Occident - dont les deux tomes ont paru à Genève en 1876 et 1878 - le comte Riant avait déjà souligné l'importance pour l'étude de ce sujet de la littérature parénétique, tout en déclarant avoir laissé de côté ce type de documents à cause du travail de dépouillement trop considérable qu'il aurait fallu mettre en œuvre pour les repérer ${ }^{1}$. Notre travail n'a pas l'ambition de pallier cette lacune, mais uniquement de tenter de mieux comprendre quels pouvaient être les thèmes abordés dans les sermons prononcés lors de la fête de la Sainte Couronne et de celle des Reliques et d'examiner quelle était la place que les prédicateurs réservaient au thème de la royauté. Pour l'essentiel, nous avons privilégiés les sermons qui datent d'avant 1274 et qui ont été prononcés à Paris, à 1a Sainte-Chapelle ou ailleurs; nous avons cependant choisi d'examiner également deux sermons prononcés pendant la première croisade de Louis IX ainsi que quelques autres sermons sur la Couronne d'épines prêchés en dehors du royaume de France.

Il est certain qu'à l'occasion des cérémonies organisées pour fêter la translation de la Sainte Couronne en 1239 et des autres reliques en 1241-42, plusieurs sermons ont été prononcés. D'après le récit de 1'archevêque de Sens Gautier Cornut, il semblerait qu'un sermon ait été prononcé à la cathédrale Saint-Étienne le jour même de l'arrivée de la Couronne d'épines, soit le 11 août $1239^{2}$. Quelques jours plus tard, le 19 août, lorsque la relique est arrivée à proximité de Paris, on sait que près de l'église Saint-Antoine on avait

\footnotetext{
${ }^{1}$ P. É. D. Riant, Exuviae sacrae costantinopolotanae. Fasciculus documentorum minorum, ad exuvias sacras constantinopolitanas in occidentem saec. XIII translatas, spectantium, et Historiam quarti belli sacri imperijque gallo-graeci illustrantium, Genève, 2 vol., 1876 et 1878. Le troisième volume, dû à F. de Mély, a paru à Paris en 1904.

${ }^{2}$ « Defertur in ecclesiam protho-martyris Stephani, populis detegitur, et tante cause iocunditatis aperitur» $(\mathrm{G}$. Cornut, Historia susceptionis corone spinee, éd. P. E. D. Riant, p. 55).
} 
construit une estrade, un « eminens pulpitum », afin que l'assistance puisse l'admirer et qu'un sermon avait été prononcé devant une foule de fidèles très nombreuse ${ }^{3}$.

Lors de la réception de la Vraie Croix en septembre 1241 et, peu après, sans doute en août $1242^{4}$, de la Croix de Victoire, de la Sainte Lance, de 1'Éponge et de quelques autres reliques, des cérémonies analogues avaient été organisées aux portes de Paris, au cours desquelles deux sermons avaient été prononcés ${ }^{5}$. D'après ce que rapporte le chroniqueur Albéric de TroisFontaines, le sermon donné le 19 août 1239 près de Saint-Antoine, aurait porté sur les grands privilèges que le royaume de France avait déjà obtenu de Dieu et souligné l'importance de celui qu'il venait de recevoir, tout en précisant que des fragments de la Couronne d'épines étaient déjà conservés à Saint-Denis et à Sens. Selon la relation anonyme de la translation de la Couronne, qui qualifie Louis IX de « notre David» et précise que le roi était venu en toute humilité pour transporter la relique « quasi archam Domini » dans sa ville de Paris, le peuple n'aurait eu droit à cette occasion qu'à un bref sermon exhortant à la pénitence et à la nécessité de s'abstenir de tout péché dans le futur, pour éviter que selon la prophétie de Tobie 'les jours de sa fête ne se transforment en jours de deuil ${ }^{6}$. Autrement dit, le sermon aurait insisté sur l'idée que le nouveau privilège qui venait d'être concédé au royaume entraînait aussi une plus grande responsabilité de chacun vis-à-vis de Dieu. Aucune source ne permet en revanche de savoir quels ont été les thèmes abordés par les sermons prononcés lors de l'arrivée de la Vraie Croix et de la Croix de Victoire, ni d'ailleurs d'identifier les prédicateurs qui ont pris la parole lors de ces différentes cérémonies.

L'archevêque Gautier Cornut qui faisait partie, comme on le sait, de l'entourage très proche de Blanche de Castille et de Louis IX, a sans doute pris la parole lors de l'arrivée de la

\footnotetext{
3 « Octava die extra muros, iuxta ecclesiam B. Anthonij, in campi planitie, construitur eminens pulpitum, astantibus pluribus prelatis, ecclesiarum conventus indutis sericis, exhibitis sanctorum pignoribus, in tanta populorum frequentia quanta unquam Parisius exierit ; monstratur loculus ex pulpito, diei felicitas et causa gaudij predicatur » (ibid. p. 55). L'auteur anonyme de la Translatio sancte corone Domini nostri Ihesu Christi évoque lui aussi la présence d'une foule immense. Le récit anonyme de la translation a été édité par E. Miller dans le premier des deux articles qu'il a consacrés à l'ouvrage de Riant parus dans le Journal des Savants de mai et juillet $1878 ; 1$ 'édition se trouve aux p. 295-302 et le passage sur la foule nombreuse à la p. 296 ; le récit a été réédité la même année par $\mathrm{N}$. de Wailly, « Récit du treizième siècle sur les translations faites en 1239 et en 1241 des saintes reliques de la Passion », in Bibliothèque de l'École des Chartes, 39 (1878), p. 408-415.

${ }^{4}$ Pour la datation des différentes translations, cf. A. Frolow, La relique de la vraie Croix, recherches sur le développement d'un culte, Paris, 1961, p. 427-30 ; Cl. Billot, «Le message spirituel et politique de la SainteChapelle de Paris », in Revue Mabillon, n. s., 2 (63), p. 120.

${ }^{5}$ Cf. Translatio sancte corone ..., éd. E. Miller, p. 297 et p. 301.

${ }^{6}$ « Congregatisque omnibus ad locum predicte ostensioni paratum, fit exortatio predicationis ad populum, in qua breviter ammonetur commissorum sordes detergere peccatorum et a commitendis precavere in posterum, ne juxta propheticum sermonem 'dies festi sui convertantur in luctum' » (ibid. p. 297).
} 
Couronne à Sens ${ }^{7}$. Mais il est peu probable que le sermon qu'il a prononcé à cette occasion soit celui qu'on trouve au début du traité qu'il a écrit sur demande du roi pour relater les circonstances de 1'achat et du transport de la relique. Il est plus vraisemblable que le sermon, qui exhorte à célébrer la fête du jour, ait été rédigé pour le premier anniversaire de l'arrivée de la Sainte Couronne dans sa ville. Aucun élément ne permet d'ailleurs de dire que le sermon a été donné en présence de la nouvelle relique et, puisque l'archevêque est décédé en avril 1241, il paraît raisonnable de penser que ce texte a été proposé aux fidèles à Sens le 11 août $1240^{8}$

Sans entrer dans les détails, l'archevêque invite tout d'abord à rendre grâce à Dieu pour le cadeau qu'il a consenti «à notre peuple et à notre royaume», dit-il, et souligne que toute l'église gallicane et le peuple des Francs doivent se réjouir d'avoir été choisis pour être le lieu de conservation de la Sainte Couronne. Grâce à Louis et à sa mère Blanche, ajoute-t-il, le Seigneur a voulu en quelque sorte couronner le royaume de France et, de même qu'il avait choisi la Terre de la Promesse pour manifester les mystères de la Rédemption, de même il a choisi «notre Gaule » pour que le triomphe de sa Passion soit vénéré avec une plus grande dévotion ${ }^{9}$. Cette comparaison est proposée de manière plus explicite également par l'auteur anonyme de la translation qui remarque que, grâce à l'arrivée de la Croix de Victoire, la ville de Paris est devenue presque une autre Jérusalem et que les reliques y sont désormais conservées «pour la gloire de Dieu et la protection du royaume», signe que ce texte a été rédigé lorsque les reliques étaient désormais à la Sainte-Chapelle ${ }^{10}$, dont 1'auteur relève d'ailleurs au passage le plan somptueux ${ }^{11}$.

L'arrivée de la Couronne d'épines et des autres reliques de la Passion a entraîné l'institution d'au moins deux fêtes : celles de la Sainte Couronne, qui à Paris avait été fixée au 11 août, et celle dite des reliques, fixée au 30 septembre. Ailleurs, la fête de la Couronne était cependant célébrée à d'autres moments de l'année liturgique: ainsi, par exemple, le

\footnotetext{
${ }^{7}$ Sur Gautier Cornut, cf. J. Richard, Saint Louis, Paris, 1983, en particulier p. 43 et p. 84-86, J. Le Goff, Saint Louis, Paris, 1996, passim ; sur le rôle de l'archevêque lors du brûlement du Talmud voir en dernier lieu A. Tuilier, «La condamnation du Talmud par les maitres universitaires parisiens, ses causes et ses conséquences politiques et idéologiques », in Le brûlement du Talmud à Paris, 1242-1244, éd. G. Dahan, Paris, 1999, p. 63-65, qui mentionne aussi un exemplum de Thomas de Cantimpré qui met en scène l'archevêque de Sens.

${ }^{8}$ Cf. N. de Wailly, «Récit du treizième siècle... », p. 406. Contrairement à ce qu'écrit N. de Wailly, il nous semble que le début de l'opuscule n'est pas un simple exorde, mais un véritable sermon qui aurait été utilisé en quelque sorte comme introduction à la partie plus proprement historique du récit.

${ }^{9}$ G. Cornut, Historia susceptionis corone spinee, éd. P. É. D. Riant., p. 45-47; le passage a été traduit en français par J. Le Goff, Saint Louis, p. 141-142.

${ }^{10}$ Cf. Translatio sancte corone ..., éd. E. Miller, p. 301. L'auteur qualifie aussi Louis IX de «David noster » et précise qu'il est venu accueillir la vraie Croix « non precioso et eminente equo subvectus » (ibid., p. 296).

${ }_{11}$ «...ubi in edificata non multo post per eundem regem basilica, pretioso scemate constructa, honorifice reservatur » (ibid., 297).
} 
lectionnaire conservé aux Archives Générales de l'Ordre des Prêcheurs à Rome, et qui peut être daté d'environ 1256, explique que les dominicains célébraient la fête de la Couronne le jour qui suivait l'Invention de la Croix car le 11 août était l'octave de la Saint-Dominique ${ }^{12}$. Au couvent dominicain de Vicence de la Sacra Corona, la fête avait été fixée au premier dimanche après l'octave de Ascension. D'après la relation anonyme de la translation, à Paris la fête de la Sainte Couronne aurait été instituée par Louis IX après l'arrivée de la Croix de Victoire, et donc vraisemblablement après août 1242, sur conseil et avec l'assentiment de l'évêque de Paris, c'est-à-dire de Guillaume d'Auvergne ${ }^{13}$.

S'il est probable qu'à Paris, aussi bien pour la fête du mois d'août que pour celle du mois de septembre, on prêchait à plusieurs endroits de la ville, et bien sûr à la Sainte-Chapelle, les sermons qui nous sont parvenus et qui peuvent être datés du règne de saint Louis ou des toutes premières années qui ont suivi sa mort, sont relativement peu nombreux. C'est principalement dans les collections de sermons léguées par Robert de Sorbon avant 1274 à la bibliothèque du collège qu'il avait fondé, qu'on trouve une dizaine de sermons qui permettent de se faire une idée des thèmes qui étaient abordés à cette occasion par les prédicateurs ${ }^{14}$. Les collections ont conservé environ 2400 sermons, dont la plupart sont des sermons pour ainsi dire 'parisiens' ou rédigés par des prédicateurs qui ont séjourné pendant des périodes assez longues à Paris. Les manuscrits ont été selon toute vraisemblance copiés à Notre-Dame ou dans des milieux proches du chapitre. On y trouve la presque totalité des sermons connus de Guillaume d'Auvergne ainsi que quelques dizaines voire quelques centaines de sermons de Philippe le Chancelier, de Guiard de Laon, d'Eudes de Châteauroux, etc ${ }^{15}$.

C'est dans le deuxième volume de la collection consacré au sanctoral qu'on trouve deux cahiers dans lesquels ont été copiés dix sermons que les rubriques désignent comme étant

\footnotetext{
${ }^{12}$ Cf. F. Lomastro Tognato, I « Monumenta reliquiarum » di S. Corona di Vicenza, Padova, 1992, p. 8, n. 2 et p. 10.

13 «Quia vero melius memorie commendatur quod frequentius iteratur, de consilio et assensu dyocesani episcopus, dictus rex statuit et decrevit ut annis sibi succedentibus iii ${ }^{\circ}$ idus augusti a Parisiensi populo sollempniter observetur... ", (Translatio sancte corone..., éd. E. Miller, p. 301-302). Guillaume d'Auvergne n'est pratiquement jamais mentionné en relation avec les reliques de la Passion et, pour des raisons que nous ignorons, n'était pas présent à la Dédicace de la Sainte-Chapelle.

${ }^{14}$ Il s'agit des manuscrits Paris. BnF lat. 15959, 15955, 15964, 16471, 15951 et 15954. Les trois premiers volumes de la collection contiennent des sermons de tempore, alors que les trois autres des sermons de sanctis et de communi sanctorum. Un septième volume, contenant des sermons ad status, ne nous est pas parvenu (cf. $\mathrm{N}$. Bériou, «La prédication synodale au XIII ${ }^{\mathrm{e}}$ siècle d'après l'exemple cambrésien », in Le clerc séculier au moyen age, Paris, 1993, p. 232, n. 13).

${ }^{15}$ La liste des incipit, avec quelques oublis et imperfections, a été établie par J. B. Schneyer, Repertorium der lateinischen Sermones des Mittelalters fuir die Zeit von 1150-1350, Beiträge zur Geschichte der Philosophie und Theologie des Mittelalters. Texte und Untersuchungen, Bd 43, 11 vol., Münster, 1969-1990, (dorénavant RLS), t. 5, p. 230-312, sous 'Robertus de Sorbonio'. La plupart des sermons datent vraisemblablement d'une période qu'on peut situer entre 1220 et la mort de Robert de Sorbon.
} 
«De sancta corona » ou dont elles précisent qu'ils ont été donnés « In festo reliquiarum » ${ }^{16}$. I1 est certain que ce petit corpus a été réuni en fonction de la fête du 11 août, car il se trouve immédiatement après les sermons prévus pour la saint Laurent et avant ceux pour l'Assomption de la Vierge. Le recueil ne comporte en revanche aucun sermon pour la fête du 30 septembre, ce qui pourrait suggérer qu'à cette époque on attachait davantage d'importance à la célébration du mois d'août ${ }^{17}$.

Les dix sermons ont été copiés par cinq copistes différents : le premier copiste a copié les deux sermons attribués explicitement à Guiard de Laon, ainsi qu'un troisième qu'on peut également rendre à l'évêque de Cambrai $^{18}$; le deuxième un sermon de Nicolas de Biard ${ }^{19}$, le troisième trois sermons d'Eudes de Châteauroux ${ }^{20}$ et les deux derniers copistes respectivement un et deux sermons anonymes ${ }^{21}$. L'étude de ce petit corpus n'est pas exempte de difficultés. Quelques sermons ne peuvent pas être attribués et la datation de la plupart demeure incertaine. De même, pour plusieurs sermons il est impossible d'établir le lieu où ils ont été donnés et pour d'autres il faut se contenter d'hypothèses difficiles à confirmer.

Le premier cahier s'ouvre par un sermon qui est attribué à Guiard de Laon, personnage assez bien connu qui a été chanoine de Notre-Dame à partir de 1221, est devenu chancelier de l'université en 1237 et évêque de Cambrai à partir de 1238 jusqu'à sa mort survenue en 1248. La rubrique qualifie le sermon 'De sancta corona', mais, à la lecture, on s'aperçoit que Guiard traite surtout de l'épine, ou d'une des épines, de la Couronne, et qu'il prêche presque certainement en présence de celle-ci.

Le sermon porte sur les quatre raisons pour lesquelles Dieu à voulu léguer cette épine aux hommes $^{22}$ : afin qu'ils l'utilisent comme un cure-dent pour débarrasser les dents des péchés

\footnotetext{
${ }^{16}$ Paris, BnF lat. 15951 , f. 115 r- $129^{\text {bis }}$.

${ }^{17}$ Cela pourrait être vrai uniquement pour le milieu où ont été confectionnés les manuscrits, car on sait grâce à Guillaume de Saint-Pathus que Louis IX essayait d'être à Paris pour la célébration du 30 septembre (« ... et lors chevaucha jusques a Paris, pour estre a la feste des saintes reliques ; car lendemain de la saint Michiel il avoit acoustumé a fere la celebracion et la feste des saintes reliques a Paris », Vie de Saint Louis par le confesseur de la reine Marguerite, éd. H.-F. Delaborde, $R H F$, t. 20, p. 75). Les sermons d'Eudes de Châteauroux en particulier ne paraissent pas correspondre à la date du 11 août, voir ci-dessous.

18 RLS, t. 5, n. 1818 et n. 1819 ; RLS t. 3, n. 325 et n. 326 ; P. C. Boeren, La vie et les auvres de Guiard de Laon, 1170 env. - 1248, La Haye, 1956, p. 271-272, n. 107, p. 286, n. 234. Le sermon qui se trouve au f. 115vb116 ra n'a été répertorié ni par J.-B. Schneyer ni par P. C. Boeren.

${ }^{19}$ RLS, t. 5, n. 1820 ; t. 4, n. 163

${ }^{20}$ RLS, t. 5 , n. 1821 et n. 1822 ; t. 4 , n. 856-858.

21 RLS, t. 5, n. 1823-1825.

22 « Huius corone habemus spinam nobis missam multiplici de causa. Prima ratio est quoniam Dominus mittit nobis illam ad dentes nostros furgandos et mundandos [...]. Secunda ratio est ad pungendum cor quasi clibano ad euacuandum saniem peccatorum et timorem superbie [...].Tercia ratio est quia hac spina nos pungit et inclauat pedem affectus currentis ad peccatum. Vnde Prou. I : pedes eorum ad malum currunt et festinant ut
} 
de langue ; afin qu'ils piquent leur cœur pour le purger de tout péché ; pour l'enfoncer dans le pied de ceux qui veulent courir vers le péché et faire en sorte qu'à cause de la douleur ils soient obligés de revenir en arrière ${ }^{23}$; et, enfin, pour qu'ils puissent se servir de l'épine comme d'une broche, par exemple celles que les moniales utilisent pour retenir le voile de 1'humilité, etc. Le sermon ne fait aucune allusion à la Sainte Couronne et paraît avoir été donné par Guiard de Laon à Saint-Denis, alors qu'il occupait encore la fonction de chancelier. Il confirme tout de même qu'avant l'arrivée de la Couronne il y avait déjà une certaine tradition, à Paris et ailleurs, de prêcher sur les reliques de la Passion, et qu'après la translation on a estimé que le réemploi de ces sermons était tout à fait envisageable.

Le deuxième sermon attribué explicitement à l'évêque de Cambrai reprend presque la totalité des thèmes développés dans le premier. Plus que d'un véritable sermon, il s'agit en réalité d'une esquisse de sermon, tout au moins dans sa partie initiale, qui n'est en fait qu'une liste de citations bibliques. Les vingt premières ont été réunies autour du mot « épine », celles qui suivent autour du mot « couronne » ou « diadème », alors que les dernières semblent avoir été retenues car elles comportent le mot ou l'idée d'époux ou d'épouse. Ce qui est plus intéressant, c'est que les citations sont présentées dans l'ordre des livres de la Vulgate et que leur place à l'intérieur des chapitres est indiquée grâce au système A-G, c'est-à-dire grâce au système utilisé par les concordances bibliques réalisées par l'équipe de dominicains dirigée par Hugues de Saint-Cher ${ }^{24}$. Puisqu'on estime généralement que c'est vers 1239 que les premières concordances bibliques ont été terminées, il semblerait que ce sermon ait été prononcé par Guiard de Laon, sans doute à Saint-Denis, alors qu'il était déjà évêque de Cambrai.

Entre ces deux sermons figure un sermon anonyme, mais qui peut être rendu au même Guiard, qui comporte un passage qui semble faire référence à la Couronne d'épines : reprenant en partie les versets 12 et 13 du Psaume 64, le sermon invite le public à regarder comment le Seigneur a couronné l'année de ce bienfait, comment les champs du Seigneur sont pleins de richesses, voyez, ajoute-t-il, la couronne de la victoire, l'abondance des vertus ;

effundant sanguinem [...]. Item alia ratione est quoniam hac spina coniungitur duo ad inuicem uel ampliora ; unde precepit Dominus fieri quinquaginta fibulas ad complandum cortinas templi ad inuicem » (Paris, BnF lat 15951, f. 115rb-va).

${ }^{23}$ Cette idée est illustrée l'exemplum suivant : «Similiter quando quis impeditur ne possit libere currere ad peccatum, configitur a Domino hac spina, sicut fabri ythalici faciunt palefridos romipetarum ; inclauant, et post unam dietam emunt illos. Quod faber ille facit per maliciam, hoc idem Dominus per misericordiam, quoniam propter infirmitates quas inmittit hominem iuuenem et lasciuum conuertit ad penitentiam et peccata dimittere facit, et cet. » (ibid., f. 115va).

${ }^{24}$ Voici le début de la liste : «Priusquam intellegerent spine et cet., Psalmus LVII f. : Item 117; Exarserunt sicut ignis in spinis de spina, Psalmus XXXI b ; Dum configitur spina, Cant. II a ; Sicut lilium inter spinas, Ecclesiastici XXVIII g » (ibid., f. 116rb). 
déjà les pacages du désert deviennent gras ; dans 1'Eglise, le Christ est ceint avec la couronne des croyants ${ }^{25}$. L'instance sur l'idée que la couronne apporte désormais de grands bienfaits pourrait suggérer que le sermon a été prononcé l'année même de l'arrivée de la sainte relique, dans un endroit que rien ne permet d'identifier mais peut-être en présence d'un auditoire féminin $^{26}$

Le sermon suivant, dû à Nicolas de Biard, a été donné selon la rubrique le jour de la fête des reliques ${ }^{27}$. Nicolas de Biard est un personnage assez difficile à cerner. On sait qu'il était un frère mendiant, mais on ne sait toujours pas s'il était dominicain ou franciscain. Auteur de deux collections de sermons qui ont connu une diffusion assez importante, ainsi que d'un recueil de Distinctiones et de la Summa de abstinentia, Nicolas de Biard parait avoir prêché surtout à Paris. Le sermon pour les reliques ne fait pas partie des deux collections, mais il a été conservé par au moins un autre manuscrit ${ }^{28}$.

Sans entrer dans les détails, on peut remarquer que le sermon, qui a pour thema le verset 37 du Psaume 36, «Garde l'innocence et considère 1'équité, car les reliques appartiennent à l'homme pacifique », a été prononcé en présence d'un auditoire qui comprenait des personnages importants ${ }^{29}$. Après avoir montré comment et pourquoi il faut garder l'innocence, le sermon développe la deuxième partie du verset thématique en distinguant trois types de reliques : celles d'Adam et d'Ève (le péché original), celles du diable (les péchés mineurs, que parfois la pénitence ne permet pas d'éliminer et grâce auxquels le diable essaye de réintroduire les péchés les plus graves) et enfin les reliques de Dieu. Sans faire preuve d'une très grande originalité, Nicolas de Biard insiste sur l'idée que la mémoire de la Passion doit inciter à la conversion, et que c'est grâce à celle-ci qu'il est possible de se libérer des vices les plus dangereux, tels que 1'avarice, la luxure ou l'orgueil. C'est dans ce contexte que le

\footnotetext{
25 « Corona nobis est incarnatio, non contumelia. Videte iam quomodo benedixit corone anni benignitatis huius, quomodo campi eius repleti sunt ubertate, uidete coronam uictorie, uirtutum copiam ; iam pinguescunt speciosa deserti credentium, corona Christus in ecclesia cingitur » (ibid., f. 115vb-116ra).

${ }^{26}$ Le début du sermon paraît en effet s'adresser à des moniales: "Non ergo de Syon eas uocat quas ad uidendum Deum uocat; uel non ad uisionem Dei. sed ad uidendum Salomonem in dyademate eas uocat. Si concluse estis, nolite egredi donec uos Christus inuitet » (ibid., f. 115vb)

27 «In festo Reliquiarum, frater. N. de byart » (ibid., f. 117rb, marge inférieure).

${ }^{28}$ Il s'agit du manuscrit Paris, BnF lat. 18081, f. 136vb-138rb. Dans ce manuscrit, la rubrique indique qu'il a été donné pour la fête des Innocents ( In festo sanctorum innocentium »).

${ }^{29}$ C'est du moins ce que laisse supposer le passage suivant : « Propter commoditatem, ut ita fructuose predicet quod omnes tangat nec alicui magno parcat, uel paruo, ut non sit sicut miluus qui non audet uolare ad gallinas uel capones, sed ubi uidet pullos ibi salit, ibi uolat. Sic cum pauperculis uetulis predicamus ibi salimus, ibi aperte hanc uel illam tangimus, sed cum predicamus magnatibus, prelatis uel aliis non audemus eos tangere, nec ad eos accedere [...].Non debet ergo predicator alicui parcere licet magnus sit, nec celare ueritatem. Debet tamen obseruare modum docendi, tempus et loco. Ideo dicebat Dauid : non abscondi ueritatem tuam a consilio multo, quasi diceret : licet multi prelati sint congregati in concilio multo, in palliamento non abscondi ueritatem ab eis » (Paris, BnF lat. 15951, f. 117va-vb).
} 
prédicateur précise que dans ce monde Dieu a toujours servi et prêché la paix et que ceux qui aiment la paix et essayent de toutes leurs forces de la promouvoir, peuvent être appelés fils de Dieu. Et il ajoute: «si je voulais louer .N., et s'il était convenable de louer un homme en sa présence, je pourrai dire, puisqu'il s'agit d'un homme de paix, que ces saintes reliques de Dieu, qui sont ici présentes, lui ont été confiées car les reliques appartiennent à l'homme pacifique ${ }^{30}$. S'il ne fait pas de doute que Nicolas de Biard prêche en présence des reliques de la Passion - il précise un peu plus loin qu'il n'est pas étonnant que notre visage se transforme à la vue de ces reliques, car même le soleil a retiré sa lumière au moment de la mort du Christ $^{31}$ - rien ne permet de savoir si le sermon a été donné à Saint-Denis ou déjà à la Sainte-Chapelle, ni d'ailleurs d'identifier avec certitude en Louis IX 1'homme de paix auquel il fait référence ${ }^{32}$

Tout comme ceux donnés par Guiard de Laon sur l'épine de Saint-Denis, les deux sermons qui pourraient avoir été prononcés lorsque les reliques de la Passion étaient déjà à Paris proposent un enseignement qui est pour l'essentiel une invitation à la conversion et à la pénitence. On n'y trouve ainsi aucune allusion à l'un ou à l'autre des thèmes qui auraient été évoqués lors de la réception des reliques, ni d'ailleurs une quelconque allusion au plus grand prestige que la royauté capétienne aurait acquis grâce à l'achat de celles-ci.

Les trois sermons suivants permettent d'en savoir un peu plus sur les circonstances précises dans lesquelles les Chrétiens du temps de Louis IX ont pu assister aux célébrations liturgiques liées aux reliques de la Passion, et entendre les prédicateurs en commenter le sens. Car les trois discours qu'Eudes de Châteauroux (1190 ?-1273) a consacrés à cette fête offrent une particularité, par comparaison avec le reste du corpus ici examiné: s'ils ont bien été copiés dans les recueils de Robert de Sorbon, ce dernier les a repris des propres collections que l'orateur, devenu cardinal, a fait réaliser à la Curie, et dont il supervise l'édition à compter

\footnotetext{
${ }^{30}$ «Et hoc est quod dicitur Mathei V : Beati pacifici quoniam filii Dei uocabuntur. Si uellem laudare .N. et fas esset hominem laudare in eius presentia, possem dicere, cum sit homo pacis, quod hee sunt reliquie sancte Dei, que hic presentes sunt, sibi sunt commisse quoniam sunt reliquie $<$ homini pacifico $>$ (suppl. om. cod.), sicut dicit presens auctoritas » (ibid. f. 119ra).

31 «Quia debent semper esse in cogitatione nostra que Deus pro nobis sustinuit, quot confusiones, quot molestie ei facte sunt. Que, si bene considerentur, non est uultus hominis qui inde non mutaretur, ut uultus qui ante erat letus, respiciens has reliquias, debet esse tristis et lacrimosus. Similiter, qui ante erat pinguis et rubicondus, debet postea pallidus et macillentus esse. Et in hiis debet esse preparatio siue ornatus uultus nostri. Nec est mirum si mutatur uultus noster in consideratione harum reliquiarum, quia inde sol mutauit faciem suam, quia obscuratus fuit in morte Domini ; et licet pro amore solis non fuerit Christus passus, tamen, quia eum fecerat, mutauit faciem suam et retraxit lumen suum » (ibid. f. 119ra-rb).

${ }^{32}$ Si la Sainte Couronne se trouvait encore à Saint-Denis, en admettant que c'est à Saint-Denis qu'on l'a déposée pendant la construction de la Sainte Chapelle, 1'homme de paix auquel fait référence Nicolas de Biard pourrait être également l'abbé.
} 
de 1260 environ $^{33}$. Leur attribution ne fait ainsi aucun doute; mieux, les renseignements procurés par la tradition manuscrite de ces collections d'auteur permettent d'avancer pour chacun une date où ce discours a été donné, de proposer des hypothèses concernant le public qui l'aura entendu, bref de contextualiser ces trois textes au plus près. Le mot « texte » doit être stricto sensu conservé à leur égard, car il est évident que le cardinal Eudes de Châteauroux a retravaillé pour l'édition ses performances orales; on peut cependant démontrer assez aisément que tous les sermons de ces collections qui se rapportent à des événements précis, et que 1'orateur réunit généralement sous 1'appellation de sermons de circonstances (« De casibus »), correspondent à une parole réelle. La carrière d'Eudes de Châteauroux et les mentions des chroniqueurs attestent suffisamment qu'il a effectivement prêché, et même que dans ce domaine, il a atteint une indéniable notoriété, dont le siècle suivant au moins devait conserver la mémoire ${ }^{34}$.

Le premier sermon a été selon toute vraisemblance prononcé à l'occasion de la consécration, le 26 avril 1248, de la chapelle haute du monument-écrin voulu par le roi pour abriter les saintes reliques du Sauveur. Toutes les sources concordent pour affirmer que le cardinal, devenu entre-temps légat pour la France de la croisade de Louis IX, a présidé cette cérémonie de dédicace, entouré des plus grands prélats du royaume et même de certains venus de l'étranger (l'archevêque de Tolède par exemple). La localisation de ce premier sermon à la Sainte-Chapelle demeure toutefois une hypothèse très probable, non une certitude, dans la mesure où le texte mentionne, parmi les reliques dont on célèbre la fête, les clous ayant servi à

\footnotetext{
33 Sur Eudes de Châteauroux et son œuvre homilétique, voir F. Iozzelli, Odo da Châteauroux. Politica e religione nei sermoni inediti, Padoue, 1994. Je me permets d'autre part de renvoyer à A. Charansonnet, "L'évolution de la prédication du cardinal Eudes de Châteauroux (1190 ?-1273) : une approche statistique », dans J. Hamesse (éd.), De l'homélie au sermon. Histoire de la prédication médiévale, Louvain-la-Neuve, 1993, p. 103-142 ; Idem, «Du Berry en Curie. La carrière du cardinal Eudes de Châteauroux (1190 ?-1273) et son reflet dans sa prédication ", dans Revue d'histoire de l'Eglise de France, t. LXXXVI (2000), p. 5-37. Tout cela repris dans Idem, L'université, l'Eglise, l'Etat dans les sermons du cardinal Eudes de Châteauroux (1190 ?1273) , Thèse dactylographiée de Doctorat d'histoire soutenue à l'université Lumière Lyon 2, octobre 2001, dir. N. Bériou. On y trouvera, volume 1 tome 2, les détails relatifs à la tradition manuscrite (p. 579-590), ainsi que, volume 2 , le texte des trois sermons, édités d'après les manuscrits d'Orléans, Bibl. Mun. 203 (désormais cité O) et Arras, Bibl. Mun. 876 (désormais cité A), respectivement aux p. 729-732 (RLS n 856 : f. 284va-285va dans $\mathrm{O}$; f. 80ra-81ra dans A) ; $742-744$ (RLS n ${ }^{\circ} 857$ : f. 285va-286vb dans O ; f. 81 ra-82rb dans A) ; 762-766 (RLS $\mathrm{n}^{\circ} 858$ : f. 286vb-288ra dans O ; f. 82rb-83va dans A). A la lecture des versions qui figurent dans les collections de Robert de Sorbon (dont le manuscrit contenant les trois sermons, Paris BnF lat. 15951, sera désormais cité P), il est apparu évident que ce dernier ou ses copistes ont eu sous les yeux la première édition des sermons du cardinal, envoyée à Paris «avant la mort d'Alexandre IV » (survenue le 25. 05. 1261) aux dires mêmes de l'orateur, et dont le manuscrit d'Orléans représente probablement tout ce qui subsiste.

${ }^{34}$ Sur les mentions par divers écrivains contemporains de la prédication d'Eudes de Châteauroux, cf. A. Charansonnet, L'université... thèse citée, p. 112 note 64 et p. 113 note 66; et sur le souvenir qu'il a laissé, voir 1'édition (Saint Louis roi de France, textes de F. Avril et M.-T. Gousset, préf. J. Richard, Paris, 1990, éd. du Chêne) du manuscrit enluminé intitulé Livre des faits de Monseigneur saint Louis, BnF fr. 2829, datant du XIV siècle, où plusieurs miniatures représentent le cardinal en train de prêcher: d'après les p. 94-95, où sont identifiées les scènes peintes, Eudes de Châteauroux est repérable aux f. 21, 36v, 43, etc.
} 
crucifier le $\mathrm{Christ}^{35}$. Or on sait qu'un saint clou, déposé à la basilique royale de Saint-Denis, était possédé par les Capétiens antérieurement aux reliques acquises par l'intermédiaire de l'empereur latin de Constantinople Baudouin, la tradition dionysienne faisant remonter cette acquisition et ce don au Carolingien Charles le Chauve. Quelques années avant l'arrivée des reliques constantinopolitaines, en 1233, le roi Louis IX avait témoigné de sa vénération à l'égard du saint clou de Saint-Denis, volé puis miraculeusement réapparu ${ }^{36}$. Philippe-Auguste avait lui aussi fait don de reliques du Sauveur à Saint-Denis ${ }^{37}$. Il n'est donc pas exclu que le premier sermon sur les reliques de la Sainte-Chapelle d'Eudes de Châteauroux, maître en théologie et orateur actif à Paris au plus tard en 1229, ait été prononcé dans la basilique dionysienne à une date et dans des circonstances différentes de celles ici proposées ${ }^{38}$. La tradition manuscrite des collections de l'auteur, si précieuse soit-elle, ne permet pas de trancher définitivement sur ce point, puisque les trois discours qu'Eudes de Châteauroux a donnés sur les saintes reliques sont déjà copiés dans la première édition produite par le scriptorium cardinalice, parue fin 1260-début 1261, et qui regroupe l'activité homilétique de l'orateur depuis au moins 1229, sinon plus tôt. Divers détails toutefois, qui seront évoqués plus loin, et surtout le contenu théologique d'ensemble de ce premier sermon, font cependant nettement pencher la balance en faveur de l'hypothèse d'abord évoquée, qu'il correspondrait à la circonstance, si importante pour le royaume de Louis IX, et de très peu antérieure au départ de son armée pour la croisade, où fut dédicacée la Sainte-Chapelle. Il était tout à fait logique qu'un prédicateur de la trempe du cardinal, qui s'était d'abord fait connaître du souverain comme maître en théologie de l'université de Paris, et lui devait probablement son ascension à la pourpre ainsi que sa première légation, tout juste renouvelée par Innocent IV pour qu'il guidât spirituellement les croisés outremer, que ce prédicateur ait aussi été choisi par le roi pour présider une telle cérémonie et lui conférer tout son sens religieux.

Les deux autres sermons posent moins de problèmes: c'est presque certainement durant l'expédition elle-même qu'ils ont été donnés, respectivement à Damiette en Egypte, où

\footnotetext{
${ }^{35}$ Le texte dit : «De numero horum testimoniorum sunt hee [c'est moi qui souligne] sacre reliquie : sancta corona, crux, clavi, sudarium, sepulchrum, spongia, ferrum lancee et alia, sicut xii lapides quod filii Israel de Iordane traxerunt testimonium perhibent quod ipsi Iordanem sicco vestigio transierunt» (éd. cit. A. Charansonnet, p. 731, lignes $56-58$; f. 120rb, P ; f. 285rb, O ; f. 80vb, A) : est-ce à dire que les auditeurs ont «ces » reliques sous les yeux ? Une telle interprétation appuierait la date et les circonstances ici proposées.

${ }^{36}$ Cf. Dom M. Félibien, Histoire de l'abbaye royale de Saint-Denys en France, Paris, réédition de 1973, p. 97 (don de Charles le chauve) ; p. 228-232 (vol et réapparition miraculeuse du saint clou). J. Le Goff, Saint Louis, donne p. 124-127 la traduction du récit de l'épisode par Guillaume de Nangis.

${ }^{37}$ Dom M. Félibien, Histoire de l'abbaye royale ... cit., p. 215-216.

${ }^{38}$ Il faudrait alors songer à une fourchette chronologique entre 1242, où l'ensemble des reliques christiques acquises par Louis IX, précisément énumérées par le sermon d'Eudes, sont à Paris, et 1248, où la SainteChapelle est achevée.
} 
1'armée chrétienne venait de débarquer, le 30 septembre 1249, puis le 30 septembre 1251 en Terre sainte proprement dite, où les croisés s'étaient transportés après la défaite et la captivité du roi en Egypte. Ils prouveraient ainsi que la mémoire des précieuses reliques n'a cessé d'accompagner les combattants et de donner à l'expédition son sens spirituel fondamental. Cette date du 30 septembre se déduit de la rubrique figurant dans les manuscrits du cardinal, valable pour les trois sermons : « in festo reliquiarum sancte capelle regis Francie », désignant ainsi la fête de ce nom célébrée en leur honneur par le palais capétien ${ }^{39}$. Quant aux années proposées, 1249 pour le second et 1251 pour le dernier des trois sermons ainsi rubriqués, leur très forte probabilité s'appuie sur des allusion textuelles, sur lesquelles on reviendra le moment venu.

Trois discours sur le même sujet, mais trois contextes fort différents, donnent ainsi sa saveur spécifique à la contribution du cardinal-légat, dans le cadre plus général de la prédication parisienne suscitée par la présence, depuis 1239, de la sainte couronne puis des autres reliques christiques dans la capitale capétienne et ses alentours.

Revenons au premier sermon de la série, qui pose on 1'a vu un problème de localisation, donc de datation. Les raisons principales qui conduisent à préférer malgré tout la SainteChapelle comme lieu, plus précisément sa consécration le 26 avril 1248, tiennent au contexte global dans lequel il s'inscrit. Eudes de Châteauroux en effet n'en est pas alors au premier de ses discours visant à faire prendre la croix aux combattants, puis à les conforter dans leur choix. De tous les prédicateurs de croisade, il est même celui qui offre la plus belle série du genre à l'historien. L'ensemble des années 1245-1248, celles de sa première légation confiée par le pape au concile de Lyon, fait alterner sermons de croisade à proprement parler, et sermons de circonstances, liés à cette expédition et son organisation ${ }^{40}$. De ce point de vue, et d'autres sources l'attestent, l'événement de la fin d'avril 1248 symbolise, outre 1'aboutissement d'un grand projet, l'unité retrouvée du royaume derrière son souverain, après la très dure année 1247 où Louis IX et son légat, malgré une familiarité ancienne et une sympathie mutuelle évidente, se sont trouvés en porte-à-faux. La cause majeure de ce malaise passager entre Regnum et Sacerdotium fut constituée par la révolte des barons français contre

\footnotetext{
${ }^{39}$ Voir supra notes 4 et 12 pour les différentes fêtes des saintes reliques et leurs dates. Eudes de Châteauroux est toujours très précis dans la rubrication de ses manuscrits, mais procède lui aussi, comme Robert de Sorbon dans ses cahiers, à des regroupements de sermons prêchés à différentes dates, lorsqu'il les édite (tout cela amplement discuté dans A. Charansonnet, L'université... thèse citée, passim). De plus, entre les années 1240 et 1260, l'accent mis sur la principale fête célébrée à la Sainte-Chapelle a pu se déplacer, voir supra note 17.

${ }^{40}$ L'ensemble de ces textes est édité par A. Charansonnet, L'université... thèse citée, volume 2 ; on en lira le commentaire Ibidem, volume 1 tome 1, p. 97-271. Une partie de ces sermons, ceux consacrés stricto sensu à la croisade, sont édités et traduits par C. Maier, Crusade propaganda and ideology. Model Sermons for the Preaching of the Cross, Cambridge, 2000.
} 
la fiscalité pontificale, révolte appuyée fermement, avec un sens aigü du réalisme politique, par le Capétien, quelque prix religieux qu'il ait accordé au grand pélerinage guerrier de sanctification qu'il mettait sur pied, quelque révérence qu'il ait eue pour le successeur de 1'apôtre Pierre et son représentant en France ${ }^{41}$.

Eudes de Châteauroux dresse lui-même la liste, dans ce premier discours, des reliques qui protègent le royaume capétien et l'expédition proche de son départ: on y trouve bien sûr la sainte couronne, entrée le 19 août 1239 à la chapelle Saint-Nicolas du Palais-Royal, portée par les deux Princes capétiens aînés, le roi et son frère Robert d'Artois; s'y ajoutent les autres reliques christiques venues ensuite, par le même canal, grossir le trésor: la vraie croix, les clous, le saint suaire, un fragment de la pierre du saint sépulcre, la sainte éponge, le fer de la sainte lance « et d'autres »" C'est à l'arrivée de la seconde série que le roi dut, pensent les historiens, concevoir le projet de la Sainte-Chapelle ${ }^{43}$, véritable reliquaire dont le programme iconographique trouve sa clef dans la verrière dite précisément «des reliques » ${ }^{44}$. Les motifs politiques de Louis IX sont désormais bien éclairés: au modèle de roi thaumaturge et sacralisé dont il hérite ${ }^{45}$, et que symbolise, aux plans architectural comme historiographique, le sanctuaire dionysien traditionnel, le souverain ajoute celui du roi représentant laïc du Christ, conforme à sa spiritualité personnelle et bien accordé à la dévotion dolente du XIII ${ }^{\mathrm{e}}$ siècle,

\footnotetext{
${ }^{41}$ Un moment fort de cette unité retrouvée, presque contemporain de la consécration de la chapelle reliquaire, est la condamnation du Talmud en mai 1248, objectif poursuivi avec acharnement par Eudes de Châteauroux, alors simple maître en théologie et chancelier de l'université parisienne, dès 1244. La très bonne connaissance de la liturgie juive dont témoignent ses trois sermons sur les saintes reliques a évidemment partie liée avec ce fait. Sur le contexte d'ensemble des années 1247-1248, cf. A . Charansonnet, L'université... thèse citée, p. 153-169. ${ }^{42} \mathrm{Cf}$. supra note 35 .

${ }^{43}$ Cf. J. Le Goff, Saint Louis, p. 146-148 ; J.-M. Leniaud et F. Perrot, La Sainte-Chapelle, Paris, 1991, p. 53 et p. $81-117$.

${ }^{44}$ Cf. J.-M. Leniaud et F. Perrot, La Sainte-Chapelle, p. 181 ; voir aussi p. 184 où les auteurs, après avoir montré que la « bande dessinée » en vitrail constituée par les 1113 panneaux figurés se répartit selon deux grands cycles, historique et spirituel, selon le schème exégétique chrétien traditionnel, insistent sur la différence qui existe pourtant entre ce programme et ceux alors connus, des $\mathrm{XII}^{\mathrm{e}}$ et début du XIII $\mathrm{e}^{\mathrm{e}}$ siècles, par exemple ceux préconisés par Suger pour Saint-Denis. Selon eux, ce qui frappe est l'importance accordée à l'Ancien Testament et le caractère historique accentué de la narration, presqu'entièrement linéaire et centrée sur la royauté, phénomène qu'ils relient aux conceptions du souverain en la matière, surtout p. 192-193; ils qualifient l'ensemble p. 187 de «vaste mise en image de la théologie de l'histoire où le roi régnant trouve tout naturellement sa place ». On discutera plus loin cette appréciation.

${ }^{45} \mathrm{M}$. Bloch. Les rois thaumaturges. Etude sur le caractère surnaturel attribué à la puissance royale particulièrement en France et en Angleterre, Paris, $1983^{2}$, demeure fondamental. Les historiens postérieurs ont logiquement nuancé les dates et analyses qu'il propose, notamment J. Le Goff qui a voulu reculer le processus de sacralisation de la royauté capétienne, lequel connaît selon lui un achèvement tardif sous sa forme pleine et originale, en gros durant le règne de Louis IX précisément (voir en dernier lieu son texte dans J. L. Le Goff, E. Palazzo, J.-C. Bonne, M.-N. Colette, Le sacre royal à l'époque de Saint Louis... , Paris, 2001, p. 19-35) : je demeure convaincu avec M. Bloch (op. cit., p. 29-30) et le témoignage de Guibert de Nogent que l'essentiel est joué dès le XII ${ }^{e}$ siècle Si une restriction s'impose, c'est plutôt que, depuis et sous l'impulsion d'Innocent III, les papes, qu'Eudes de Châteauroux représente, ont stimulé une tendance concurrente, au moins aussi forte, à la désacralisation du pouvoir laïc, cf. R. Folz, "Le sacre impérial et son évolution (VI'-XIII siècle) », dans $L e$ sacre des rois. Actes du colloque international d'histoire sur les sacres et couronnements royaux (Reims, 1975), Paris, 1985, p. 89-100.
} 
notamment celle des Ordres mendiants, pour l'humanité souffrante et humble du Sauveur; une nouvelle chapelle royale, à l'image de ce que Charlemagne a fait construire à Aix, s'avère nécessaire ${ }^{46}$.

La disposition du programme iconographique des vitraux ne doit donc rien au hasard ${ }^{47}$. Au nord et au sud, du côté de la nef ${ }^{48}$, figurent les scènes historique de la Vulgate ${ }^{49}$, car c'est là que se tient le public laïc présent aux cérémonies ${ }^{50}$; le sens en est limpide: inscrire la royauté capétienne dans la continuité historique des rois oints de la Bible, ce qui explique la présence côté sud, en conclusion de ces vitraux, de scènes d'histoire contemporaine ${ }^{51}$. A l'est, du côté du chœur où se déroule la célébration liturgique, les scènes figurent, de part et d'autre de la Passion du Christ, les prophètes et les apôtres: même ici, le Nouveau Testament tient beaucoup moins de place que l'Ancien, les deux Jean, le Baptiste et l'Evangéliste, étant présentés davantage comme prophètes que comme saints ${ }^{52}$. Si le côté sud ne suit pas, contrairement aux verrières du nord, l'ordre des livres bibliques ${ }^{53}$, c'est que le concept que le commanditaire a voulu exprimer est celui de la persona mixta du souverain, à la fois roi et prêtre sur le modèle de Melchisedek ${ }^{54}$ et du Christ: ce dernier guide Louis IX, qui lui-même conduit son peuple au salut; cet aspect est particulièrement net en face de ces dernières scènes, dans la verrière des Nombres située juste au-dessus de la niche où le roi prenait place: scènes d'onction et évocations sacerdotales, associant Moïse et Aaron, signifient sans

\footnotetext{
${ }^{46}$ Sur la culture historique et la spiritualité du roi, voir en particulier J. Le Goff, Saint Louis, p. 141 et p. 858886 ; J.-M. Leniaud et F. Perrot, La Sainte-Chapelle, p. 188-191. Ces derniers citent la lettre d'Innocent IV du 24 mai 1244 où le pape écrit au roi que c'est le Christ lui-même qui le couronne à l'occasion de cette translation (éd. P. E. D. Riant, Exuviae ... , p. 128-129) : « ...nec immerito reputamus, quod te Dominus in sua Corona spinea, cuius custodiam ineffabili dispositione tue commisit excellentie, coronauit »; il faut ici faire la part de la rhétorique propre à la chancellerie pontificale, surtout lorsqu'on connaît les positions théocratique de ce pape ; et celles des circonstances, puisqu'Innocent IV, qui séjourne alors à Lyon pour préparer le concile devant déposer Frédéric II, ne peut se passer de l'appui du Capétien (cf. A. Melloni, Innocenzo IV. La concezione e l'esperienza della cristianità comme regimen unius personae, Gênes, 1990, p. 80-131).

${ }^{47}$ On suit ici l'analyse détaillée de J.-M. Leniaud et F. Perrot, La Sainte-Chapelle, p. 131-181, quitte à revenir ensuite sur leur interprétation d'ensemble.

${ }^{48}$ Voir Ibidem, p. 124, le plan qui permet de suivre le commentaire

${ }^{49}$ L'ordre suit celui des livres de la Bible au nord, mais non au sud, voir les explications ci-dessous.

${ }^{50}$ Ibidem, p. 184.

51 Ibidem, p. 192 ; la verrière est celle dite «des reliques », où figure Louis IX avec les instruments de la Passion.

52 Ibidem, p. 184.

${ }^{53}$ Dans l'ordre, des scènes de Tobie, Judith et Esther précèdent celles des Livres des Rois, juste avant la verrière des reliques.

${ }^{54}$ Ibidem, p. 192-193. Sur la figure de Melchisedek, cf. G. Wuttke, Melchisedech der Priesterkönig von Salem : eine Studie zur Geschichte der Exegese, Giessen, 1927; J. Funkenstein, « Malkizedek in der Staatslehre », dans Archiv für Rechts- und Sozialphilosophie, t. XLI (1954), p. 32-36; R. E. Lerner, « Joachim of Fiore as a Link between St. Bernard and Innocent III on the Figural Significance of Melchisedech », dans Mediaeval Studies, t. XLII (1980), p. 471-476 (trad. Italienne, « Gioacchino da Fiore comme legame fra san Bernardo e Innocenzo III sul significato simbolico di Melchisedech», dans Idem, Refrigerio dei santi. Gioacchino da Fiore $e$ l'escatologia medievale, Rome, 1995, p. 137-143).
} 
équivoque cette mixité de la personne du souverain ${ }^{55}$. La fonction eschatologique du Capétien, guidant son peuple vers le Jugement, achève de trouver son expression dans la rosace de l'Apocalypse à l'ouest, redoublée à l'extérieur du bâtiment par la représentation du Jugement dernier sur le tympan. C'est bien 1'Histoire, et à travers elle l'influence du renouveau de l'exégèse littérale à partir du second XII ${ }^{\mathrm{e}}$ siècle, qui est au centre de cette composition $^{56}$; de ce point de vue la présence des prophètes au milieu des scènes historiques ne constitue pas une rupture: d'une part parce que l'histoire et la prophétie, entendue dans son sens orthodoxe, ne sont pas de nature fondamentalement différente au Moyen âge ${ }^{57}$; d'autre part parce que l'exégèse, Eudes de Châteauroux en fournit moult exemples, applique fréquemment les prophéties ou les actions de personnages historiques de 1'Ancien Testament aux circonstances contemporaines. Cette notion de la continuité historique entre royauté d'Israël et royauté capétienne ouvre le texte des indulgences que les prélats présents à la consécration, six archevêques et onze évêques, concèdent aux visiteurs en avril $1248^{58}$. Il est clair que la croisade n'a pu que conforter et accélérer la réalisation d'un tel programme, puisqu'elle constitue la première étape de cette marche vers le Royaume.

Cette vision de l'Histoire et du sens précis de la croisade semblent largement partagée par le légat, à lire le sermon pour la fête des saintes reliques qu'il délivre, selon 1'hypothèse proposée, le 26 avril 1248, à l'occasion de la consécration officielle de la Sainte-Chapelle, et qui apparaît à beaucoup d'égards comme un exposé théologico-historique des vitraux que les présents ont sous les yeux ${ }^{59}$. Le texte en est très proche par l'esprit de celui des indulgences

\footnotetext{
${ }^{55}$ Toutes ces analyses procèdent fondamentalement d'E. Kantorowicz, Les deux corps du roi. Essai sur la théologie politique au Moyen âge, Paris, 1989 (traduction de The King's two Bodies. A Study in Mediaeval Political Theology, Princeton, 1957). Un bel exemple de cette assimilation au type de Melchisedech figure dans une enluminure du Psautier de saint Louis (manuscrit de Paris, BnF lat. 10525, f. 6v), reproduite dans J.-M. Leniaud et F. Perrot, La Sainte-Chapelle, p. 95.

${ }_{57}^{56}$ 'est là le fil rouge de B. Smalley, The Study of the Bible in the Middle Ages, Oxford, $1984^{2}$.

${ }^{57}$ Sur la nature de l'histoire et son apparentement à la prophétie, voir B. Guenée, Histoire et culture historique dans l'Occident médiéval, Paris, 1980, surtout p. 20s. En faveur de la prophétie qu'on peut qualifier d' « orthodoxe », par opposition à une exégèse prophétique dissidente, voire hérétique, le plus souvent à usage politique elle aussi, Eudes de Châteauroux devait s'engager très fortement quelques années plus tard, lors de la sévère bataille théologico-politique qu'il eut à mener pour défendre l'orthodoxie, contre 1'Introduction à l'Evangile éternel du Franciscain Gérard de Borgo San Donnino, s'inspirant lui-même de Joachim de Fiore, puis contre les partisans impériaux et leurs manifestes prophétiques attribués à Joachim, dans le cadre de la conquête du royaume de Naples par Charles d'Anjou, frère de Louis IX (voir A . Charansonnet, L'université ... thèse citée, p. 279-384).

58 Ed. J. de Laborde, Layettes du Trésor des chartes, t. III, Paris, 1875, p. 26, n 3652 : « Si populus Israel, qui sub legis umbra viuebat, frequenter accedens oraturus ad locum quem elegit Dominus ut ibi poneret nomen suum, vota et denaria plurima offerebat, multo fortius populus christianus... tenetur ecclesias... congruis honoribus frequentare... Sane, cum capella illustrissimi Regis Francorum ... fuerit a reuerendo patre Odone, Dei

gratia Tusaculanensi episcopo, legato sedis apostolice, nobis eidem assistentibus, dedicata...".
59 Pour en finir avec les problèmes de datation de ce sermon, si la fin d'avril 1248 paraît hors de doute, on ne peut affirmer que le discours a été donné le jour même de la consécration, car si le rôle majeur d'Eudes de Châteauroux lors de cette cérémonie est assuré (voir note précédente), aucune source ne mentionne explicitement
} 
qu'il concède le 27 mai 1248, où il rappelle sa consécration et adopte un ton très personnel ${ }^{60}$. Mais 11 souligne dans son discours, avec beaucoup plus de netteté que ne semblent le faire les vitraux, du moins si l'on s'en tient à l'analyse du monument proposée ci-dessus, la nature fondamentalement différente de la Nouvelle Alliance inaugurée par le Sauveur, notamment la supériorité des rites et des reliques chrétiens sur ceux dont a hérité le Judaïsme; le contexte contemporain de la condamnation du Talmud interdit de négliger ce contraste.

Un autre sermon de croisade, de peu antérieur, exaltait le bois de la croix ${ }^{61}$; celui-ci illustre la même réflexion théologique sur la Passion du Christ, attribuée sans doute trop unilatéralement à l'influence du cercle mendiant royal. Au-delà des vitraux à strictement parler, l'ensemble de la chapelle-reliquaire où il est prononcé constitue un hymne à ce mystère central de l'économie du salut chrétien, puisque quatre éléments structurent le message religieux de l'édifice ${ }^{62}$ : la châsse contenant les reliques, où sont représentées la Crucifixion, la Flagellation et la Résurrection; les vitraux; la retombée des arcs, où figurent les apôtres, rarement présents dans les chapelles palatines existant antérieurement ${ }^{63}$; des scènes de martyre dans des médaillons peints. Or tout le sermon d'Eudes de Châteauroux, chef spirituel de la croisade, à la Sainte-Chapelle, est centré sur la succession PassionRésurrection-Rédemption, exactement comme la châsse contenant les reliques ${ }^{64}$. Sa valeur n'en est que soulignée.

Le caractère unique de la venue sur terre du Sauveur structure en deux parties le discours, en considérant dans un double sens littéral un verset des Psaumes, livre biblique cher au roi ${ }^{65}$ :

un sermon de sa part le jour de la dédicace. De plus, l'orateur dans l'édition de ses sermons en a regroupé un certain nombre sous la rubrique des dédicaces d'églises; or les trois sermons pour la fête des saintes reliques forment un groupe distinct de cet autre pour les dédicaces, au sein même des sermons « de circonstances » («De casibus » dans les manuscrits).

${ }^{60}$ Cf. 1'éd. P. E. D. Riant, Exuviae ..., p. 136-137: « ... unde noster animus, in quadam magna extasi pre ammiratione suspensus, quodam modo expauescit, quia non potest tanta Dei magnalia dignis attollere laudibus, vel debita honorificencia resonare, licet assurgamus ad quas possumus gratiarum actions multiplices exsoluendas; nos volentes ut eadem capella, quam in honore sante Corone ac victoriossime cruces prefatis consecrauimus, in octauis Resurrectionis dominice...".

${ }^{61} \mathrm{Cf}$. A . Charansonnet, L 'université... thèse citée, édition du texte p. 697-699 ; commentaire p. 115-119.

${ }^{62}$ Cf. J.-M. Leniaud et F. Perrot, La Sainte-Chapelle, p. 94-96.

63 Ibidem, p. 96 ; les auteurs lisent à juste titre dans cette innovation la volonté d'insister sur le compagnonnage terrestre du Christ et la valeur de symbole ecclésiologique du collège apostolique.

${ }^{64}$ Cf. R. Branner, "The Grande Châsse of the Sainte-Chapelle », dans Gazette des Beaux-Arts, t. LXXVII (1971), p. 5-18, surtout p. 15s., où l'auteur démontre que la châsse n'est pas uniquement un reliquaire, réalisant l'équation politique couronne royale = couronne d'épines, mais aussi un manifeste exaltant le dogme de la Rédemption: "C'était plutôt le thème de la rédemption, Christ comme source de grâce à travers lequel 1'humanité serait rachetée, Christ le prêtre-victime, médiateur des activités rédemptrices de Dieu... »; voir aussi la conclusion de l'auteur p. 16 sur la signification globale de la décoration de la châsse. Compléter, pour la position de la Grande Châsse à l'intérieur du sanctuaire, par C. Reynolds et J. Stratford, « Le manuscrit dit 'Le pontifical de Poitiers' », dans Revue de l'Art, t. LXXXIV (1989), p. 61-80.

65 Et qui réside à la base de 1'éducation religieuse, puisque c'est là que les enfants chrétiens apprenaient à lire, cf. D. Alexandre-Bidon et D. Lett, Les enfants au Moyen âge, $V^{e}-X V^{e}$ siècles, Paris, 1997, p. 85-86. 
«Merveilleux sont tes témoignages, aussi mon âme les scrute »; c'est au sens strict du terme la littera, entendue comme l'étude grammaticale du sens des phrases, qui détermine les deux significations possibles de la citation: «tes merveilles, c'est à dire ce qui témoigne de toi », ou bien: " tes merveilles, c'est à dire ce dont tu portes toi-même témoignage » ${ }^{66}$. La suite du texte traite sans les distinguer explicitement ces deux catégories de témoignages; on s'aperçoit cependant que les opera du Seigneur se rapportent à la première catégorie, et ses verba à la seconde, de sorte que 1'orateur suit en fait deux pistes: la première interprétation mène à contempler la création, la seconde à considérer la rédemption que le sacrifice du Christ a procuré aux hommes; l'introduction appuie ces deux interprétations par quatre citations de 1'Evangile de Jean ${ }^{67}$ : on ne peut établir plus clairement le lien entre ancienne et nouvelle lois, entre Ancien et Nouveau Testaments ${ }^{68}$. Le premier point du sermon consiste en une réflexion théologique sur la création, reprenant la conception augustinienne que l'apparence des créatures donne une idée du Créateur, qui en disposant tout en ordre, en poids et en mesure, a montré sa puissance, sa sagesse et sa bonté; de même Il a montré son éternité en créant tout sans que le principe de sa création puisse être compris des hommes, ainsi que son unicité, en étant au principe de tout le créé ${ }^{69}$. Le second point aborde les oeuvres de la « recréation ${ }^{70}$ et compte au nombre de ces œuvres les saintes reliques énumérées: la sainte couronne, la croix, les clous, le suaire, le sépulcre, l'éponge, le fer de la lance, et d'autres encore; le caractère de preuves matérielles que ces reliques revêtent est souligné par un parallèle avec l'Ancien Testament: dans Josué (4, 1 s.), les fils d'Israël ont extrait douze pierres du Jourdain pour

\footnotetext{
${ }^{66}$ Sur la « littera », cf. G. Dahan, L'exégèse chrétienne de la Bible en Occident médiéval, XII -XIV siècle, Paris, 1999 , p. $242-262$.

${ }^{67}$ A . Charansonnet, L'université ... thèse citée, édition p. 729 : « Hoc duobus modis poteste intelligi. Mirabilia testimonia tua (Ps. 118, 129), id est que de te testantur, vel ea que tu ipse testaris. Testimonia enim que de ipso Domino testantur mirabilia sunt et ideo perscrutanda. Testantur enim de Domino non tantummodo verba, immo opera, que sunt testimonia valde credibilia ; immo talia que homo non potest non credere, et quibus humana ratio aliquam tergiversacionem non potest contradicere. Unde Iohanne $\mathrm{v}^{\circ}$ : Opera que ego facio testimonium perhibent de me (Io. 5, 36). Et in eodem : Scrutamini scripturas in quibus putatis vitam eternam habere, ille sunt que testimonium perhibent de me (Io. 5, 39). Et in eodem : Qui misit me Pater perhibet de me (Io. 5, 37). Et in eodem : Vos misistis ad Iohannem et ipse testimonium perhibuit veritati $($ Io. 5,33$) »$.

${ }^{68}$ Ici comme ailleurs, Eudes de Châteauroux aborde le sens littéral d'un point de vue englobant, très caractéristique de 1'évolution de 1'herméneutique biblique à partir d'Hugues de Saint-Victor ; à strictement parler en effet, le Nouveau Testament n'est pas susceptible d'interprétation historique au sens traditionnel de 1'expression, c'est à dire comme annonçant les événements à venir, s'accomplissant dans une révélation, puisqu'il est lui-même la Révélation. Il ne peut que narrer la vie et les paroles du Christ venu sauver les hommes ; à moins de s'engager dans la direction, potentiellement dangereuse, d'une lecture prophétique de cette partie de la Bible et plus particulièrement de l'Apocalypse, comme s'y sont risqués divers exégètes, mais particulièrement Joachim de Fiore à la fin du XII ${ }^{\mathrm{e}}$ siècle.

${ }^{69}$ Cf. A . Charansonnet, L université ... thèse citée, édition p. $730:$ «Ostendit enim se esse eternum, quia illud per quod facta sunt omnia non potest intelligi esse factum. Similiter, per quod omnia sumpserunt exordium, exordium habere non potuit. Et quia omnis numerus ab unitate incipit, oportuit ut ille a quo omnia [sunt] sit unicus. Sic ergo opera creationis quedam testimonia sunt Domini ».

${ }^{70}$ Ibidem, édition p. 731 : «Opera vero recreationis sunt testimonia mirabilia Domini, quod nos diligat... ».
} 
prouver qu'il l'avaient effectivement traversé à pied $\sec ^{71}$. La proximité du départ en croisade comme de la condamnation définitive, à peu près contemporaine, du Talmud, se devinent quand l'orateur affirme avec habileté que «C'est là l'œuvre de rédemption, un témoignage d'amour du Seigneur si violent que les Juifs, les Sarrasins et les autres infidèles ne peuvent croire que Dieu ait aimé les hommes à ce point $\rangle^{72}$. La comparaison de la même croisade avec 1'Exode est implicite et assimile le peuple de France aux Hébreux; avec toutefois un avantage aux Chrétiens, car après l'évocation des grandes étapes de la fuite d'Egypte et de la traversée du désert, où Dieu a nourri Israël et ouvert devant elle la Mer Rouge, l'auteur conclut que «Les fils d'Israël tenaient en grande vénération ces témoignages, la manne, la verge, les tables et le deutéronome; en beaucoup plus grande vénération devons-nous tenir ces témoignages que nous avons sous la main..., car ils sont de bien plus de valeur que ceux-là, eux qui témoignent de notre rédemption et de l'amour ineffable dont Dieu nous a aimés ${ }^{73}$.

Le principal mérite de cette comparaison des deux Testaments ne consiste donc pas simplement à situer la royauté capétienne dans le droit fil de la royauté biblique, ce qui minorerait la signification théologique du sacrifice du Christ; sa valeur, rappelée dans les menus détails concrets que chaque relique signifie, marque un degré supérieur par rapport à 1'amour que le Dieu de l'Ancien Testament avait montré pour son peuple, en le soutenant dans les épreuves et en l'instruisant.

Ce saut qualitatif d'un Testament à l'autre est bien l'exact correspondant du «saut herméneutique » accompli par l'exégète lorsqu'il interprète spirituellement la Bible. Un public en large part laïc se voit ainsi invité à retrouver, sous une forme renouvelée car beaucoup plus concrète, matérialisée, celle des instruments de la Passion, le sens de la Bible

\footnotetext{
${ }^{71} \mathrm{Cf}$. supra note 35 .

${ }^{72}$ Cf. A . Charansonnet, L'université... thèse citée, édition p. 731 : « Hoc est opus redempcionis, quod est adeo violentum testimonium amoris Domini, quod Iudei, Sarraceni et alii infideles credere non possunt quod Deus homines tantum dilexerit ». On notera ici la mise sur le même plan des Juifs et des Sarrasins, éloquente : c'est bien la preuve que l'affaire du Talmud a profondément ébranlé la vision que l'auteur se fait de la Synagogue et de son rôle historique, cela d'autant plus que les développements qui suivent enchaînent les parallèles avec 1'histoire du peuple hébreu et des témoignages de sa foi, qui préfigurent ceux du Christ. Du point de vue théologique toutefois, le rapprochement entre Juifs et Sarrasins n'apparaît pas comme purement polémique : ce que ces deux peuples rivaux monothéistes refusent d'admettre, nous dit 1'auteur, c'est 1'Incarnation. Les Chrétiens, on le sait, avaient bien conscience que Judaïsme et Islam convergeaient pour dénoncer leur « faux » monothéisme, cf. N. Daniel, Islam et Occident, Paris, 1993, en particulier p. 237-259.

${ }^{73} \mathrm{Cf}$. A . Charansonnet, L'université... thèse citée, édition p. 731 : « In magna veneracione habebant filii Israel ista testimonia, Mahu scilicet, virgam et tabulas et Deuteronomium. In multo maiori debemus habere ista testimonia que pre manibus habemus, sanctam coronam scilicet et crucem etc., quia multo maioris rei sunt hec testimonia quam illa, scilicet redempcionis nostre et tam ineffabilis dielctionis qua Deus dilexit nos ».
} 
conduisant à la compréhension du mystère divin: par là le Chrétien s'identifie au Christ qui l'a créé puis recréé ${ }^{74}$.

On ne saurait sous-estimer la densité du commentaire et du message, inscrit dans la tradition de la méditation de la Passion, mais renouvelé des tendances historicisantes de 1'exégèse comme de la spiritualité doloriste du XIII ${ }^{\mathrm{e}}$ siècle ${ }^{75}$; synthèse qui donne sa pleine dimension eschatologique à la croisade.

Le second sermon doit être placé dans un contexte très différent du précédent. L'armée chrétienne vient de débarquer à Damiette, choisie comme tête de pont, puisque 1'objectif est de mettre à la merci les Egyptiens en marchant sur Le Caire ou Alexandrie. Heureux présage, quasi miracle, la ville est tombée sans presque de résistance ${ }^{76}$; par contre, avant de poursuivre son expédition, le roi attend le renfort de son frère Alphonse de Poitiers, qui tarde. Début octobre 1249 , sur le conseil de Joinville qui a vu un autre prélat pratiquer ainsi avec succès, alors que le navire où le sénéchal se trouvait était égaré en mer, Eudes de Châteauroux fait « crier » trois processions trois samedis de suite, pour hâter la venue du comte et protéger son voyage $^{77}$. Le chroniqueur précise que les deux premiers samedis, le légat donne un sermon devant le roi et les barons, à qui il accorde une indulgence plénière ${ }^{78}$.

Il serait tentant de faire correspondre le second sermon conservé dans les manuscrits avec l'un des deux discours du légat évoqués par Joinville. La rubrique, « in festo sanctorum reliquiarum », ne concorde cependant ni avec le 9 octobre ni avec le 16, mais suggère que la date la plus probable pour ce sermon est le 30 septembre 1249. Qu'il s'agisse d'un sermon donné durant la croisade, ce sont les termes mêmes de l'orateur qui le suggèrent, car il apostrophe ainsi les croisés: « Ainsi le Seigneur a-t-il ces temps-ci enivré le roi de France, ses frères, ses soldats et le peuple de ce même royaume afin de faire d'eux sa volonté; si en effet

\footnotetext{
${ }^{74} \mathrm{Cf}$. A . Charansonnet, L'université... thèse citée, édition p. 732 : «Et ideo ista testimonia valde sunt mirabilia. Et ideo ea debemus corde intentissimo perscrutari et ea habere pre oculis ut nos inflamment ad amorem Dei et inducant nos et stimulent ut ei vicem pro nostro modulo repandamus, ut ille qui nos creauit et recreauit nos glorificet Thesus Christus... ». .

${ }^{75}$ Voir dans ce sens B. Smalley, The Study...op. cit., p. 284s., sur le désir d'imitation «aussi littérale que possible » du Christ par François d'Assise.

${ }^{76}$ Cf. pour les sources chrétiennes J. Richard, «La fondation d'une église latine en Orient par saint Louis : Damiette », dans Bibliothèque de l'Ecole des Chartes, t. CXX (1962), p. 39-54; J. Monfrin, « Joinville et la prise de Damiette (1249) », dans Comptes rendus de l'Académie des Inscriptions et Belles Lettres (1976), p. 268285 ; pour le point de vue consonnant des sources musulmanes, A.-M. Eddé, "Saint Louis et la Septième croisade vus par les auteurs arabes », dans Cahiers de recherches médiévales, t. I (1996), p. 65-92, article repris dans F. Micheau (art. réunis par), Les relations des pays d'Islam avec le monde latin du milieu du X siècle au milieu du XIII siècle, Paris, 2000, p. 72-111.

${ }^{77}$ Cf. Joinville, Vie de saint Louis, éd. J. Monfrin, Paris, 1995, § 180 ; la date fournie par le chroniqueur est : « après la Saint-Rémi », fêtée le premier octobre. Les samedis qu'il évoque pourraient en toute hypothèse tomber les 9, 16 et 23 octobre 1249, puique le 24, le comte de Poitiers est arrivé à Damiette, Ibidem, $§ 182$.

${ }^{78}$ Ibidem, $§ 181$.
} 
ils n'avaient pas été enivrés, ils n'auraient pas pris la croix ${ }^{79}$. Une autre allusion, déjà évoquée, prouve que le sermon est prononcé très probablement en Egypte, devant Damiette à peine conquise, car Eudes de Châteauroux, évoquant le débarquement des croisés, s'exclame: «Quelle plus grande audace peut exister, que d'attaquer le paganisme là où sa puissance était la plus grande ? " ${ }^{80}$; outre que ce passage confirme le caractère stratégique d'une attaque contre le sultanat ayyubide d'Egypte, on note l'usage du passé (« là où sa puissance était la plus grande »), signe que le débarquement devant Damiette a déjà eu lieu. La date du 30 septembre proposée pour ce sermon a déjà été justifiée d'après la rubrique: seule la fête de cette date, parmi les nombreuses solennités liturgiques dont la venue des reliques du Christ en France avait donné l'occasion, porte exactement ce nom ${ }^{81}$. Insistons: l'armée chrétienne, durant son séjour à Damiette, doute malgré ses succès initiaux, dans la mesure où les renforts que doit conduire Alphonse de Poitiers, frère du roi, n'arrivent pas; le ton du sermon, qui cherche visiblement à réconforter les croisés, correspondrait bien à un tel climat, fin septembre 1249. Pour expliquer la discordance entre ces déductions et les dates procurées par Joinville, on peut songer à une erreur de mémoire du chroniqueur, qui écrit longtemps après les faits, ou encore à un respect dans l'esprit, mais non à la lettre, du temps de la liturgie par lui.

Quoi qu'il en soit, Joinville se rappelle que durant cette période, à la veille du départ pour les terres inconnues du sud égyptien, le légat a prêché, et il n'est pas indifférent que le sermon de croisade qui paraît se rapprocher le mieux de ces dates soit consacré aux plus saintes

\footnotetext{
${ }^{79}$ Cf. A. Charansonnet, L'université... thèse citée, édition p. 745 : « Sic Dominus inebriauit hiis temporibus regem Francie, fratres eius, militiam et populum eiusdem regni ut de eis faciat voluntatem. Nisi enim fuissent inebriati, crucem non assumpsissent $\gg$. On notera une autre allusion, qui confirme que nous ne sommes plus en France : à la fin du texte, l'orateur, pour illustrer les bienfaits spéciaux que Dieu a accordé aux Chrétiens, se donne lui-même en exemple; il déclare : «Il [Dieu] m'a donné de faire des études, alors que mes concitoyens, qui possédaient davantage de moyens que moi pour payer un séjour aux écoles, ne l'ont pas fait ; il m'a donné d'entendre l'Ecriture sacrée ; de fréquenter une agréable société, d'être promu prêtre, de devenir par sa volonté son prédicateur et d'être conduit ici avec vous [c'est moi qui souligne] ; il m'a fait votre pasteur » (éd. cit. p. 746 : «Et ut de aliis taceam, de me possum ponere exemplum. Dedit michi Dominus ut essem in studio, quod non est datum conuicaneis meis qui plura habebant de quibus in scolis poterant habundantius sustentari. Dedit michi ut audirem sacram scripturam, quod fui in bona societate, quod promouit me in sacerdotem, quod voluit et fecit me predicatorem suum, quod adduxit me hic vobiscum. Fecit me pastorem vestrum »).

${ }^{80} \mathrm{Cf}$. A. Charansonnet, L'université... thèse citée, édition p. $745:$ : Item vinum audaces facit. Que maior audacia quam aggredi paganismum ex illa parte in qua erat amplior fortitudo ? »

${ }^{81}$ Cf. C. Billot, « Le message spirituel... », p. 126 pour les trois fêtes fondées par Louis IX en 1244-1246 (et supra note 4) : le 11 août, la susception de la Sainte Couronne; le 30 septembre, la fête dite des "saintes reliques », correspondant à l'arrivée d'un grand fragment de la vraie croix avec d'autres reliques; le 3 août, la fête de la Croix de la Victoire, correspondant à son arrivée le 3 août 1242 avec la sainte Lance et la sainte Eponge; à quoi il faut ajouter les deux fêtes traditionnelles de l'invention (3 mai) et de l'exaltation (14 septembre) de la croix, ainsi que la fête de la dédicace du 26 avril.
} 
reliques que possède le royaume capétien, celles du Seigneur, dont une partie au moins a été transportée avec l'expédition si l'on se fie aux chroniqueurs ${ }^{82}$.

Le début du sermon est très différent de celui prononcé pour la dédicace de la chapelle haute en 1248: ce dernier était introduit, de la façon la plus classique, par les deux modes, c'est à dire les deux sens de 1'Ecriture, selon lesquels le thème biblique du sermon était à entendre; ici, Eudes de Châteauroux part bien du thème biblique qu'il a choisi, tiré d'Osée, mais pour interpeller ses auditeurs: «Vous savez, très chers, qu'aujourd'hui, nous célébrons la fête des saintes reliques que le Seigneur nous a léguées comme une sorte de mémorial de ce qu'il a réalisé et accompli pour nous... » ${ }^{83}$; tout le premier paragraphe du texte insiste sur cette fonction mémoriale des reliques christiques, joliment comparées au début du premier point du développement au cadeau que 1'ami nous fait pour que nous conservions son souvenir ${ }^{84}$. Signe que les croisés sont enfin parvenus au terme de leur quête, la reconquête des lieux où le Christ a vécu, l'exégèse du verset biblique choisi comme thème est entièrement littérale: sans aucun doute possible pour sa première partie («memoriale eius »); exégèse littérale de fait pour la seconde partie, car l'interprétation du 'vin du Liban' n'est pas allégorique au sens exact, mais métaphorique (ces reliques comme le vin du Liban doivent nous enivrer), incluse à ce titre dans le sens littéral tel que le mouvement exégétique du XIII ${ }^{\mathrm{e}}$ siècle l'a redéfini en l'élargissant $^{85}$. Le texte est entièrement structuré sur la fonction de mémoire: alors que le sermon de 1248 à Paris fonctionnait sur la scansion création-rédemption, en plein accord avec l'iconographie du lieu où il prenait place, la Sainte-Chapelle, celui-ci ne dit rien de la

\footnotetext{
${ }^{82}$ L'orateur évoque ces reliques comme si une partie d'entre elles au moins étaient sous les yeux des auditeurs (cf. A . Charansonnet, L'université... thèse citée, édition p. 744): «Has [c'est moi qui souligne] sanctas reliquias : crucem, sanctam coronam... ». Les chroniqueurs décrivent effectivement le légat, lors de l'entrée dans Damiette, portant la sainte Croix, cf. Ibidem, volume 1 tome 1, p. 221 note 140. Par ailleurs, cette énumération pose un problème : $\mathrm{O}$ et $\mathrm{P}$ donnent la même liste de reliques, respectivement aux f. 286ra et 121 ra ( « ... crucem, sanctam coronam, peplum eiusdem et pannos infancie saluatoris et alia pignora »); A, plus tardif, qui reprend les sermons de $\mathrm{O}$ mais en ajoute de nouveaux, complète ainsi la liste (f. 81va): «... crucem, sanctam coronam, ferrum lancee, pallium, sanguinem, arundinem, syndonem, lac virginis gloriose, peplum eiusdem et pannos infancie saluatoris et alia pignora ». La différence principale pourrait être constituée par l'absence du saint Sang dans la première version, alors qu'à cette époque (années 1240-1250), une polémique sur l'authenticité de cette relique sévit dans le milieu des théologiens, polémique qui a débuté lorsque le roi d'Angleterre Henri III, dans une volonté quasi explicite de faire pièce au trésor amassé par Louis IX à la Sainte-Chapelle, a fait don en 1247 d'une relique de ce type, à lui offerte par le patriarche de Jérusalem, aux moines de Westminster (voir en dernier lieu N. Vincent, The Holy Blood. King Henry III and the Westminster Blood Relic, Cambridge, 2001).

${ }^{83} \mathrm{Cf}$. A. Charansonnet, L'université... thèse citée, édition p. $742:$ :Scitis Karissimi quod hodie celebramus festiuitatem sanctarum reliquiarum quas Dominus nobis reliquit quasi quoddam memoriale eorum que pro nobis pertulit atque gessit ».

${ }^{84}$ Les mots précis de l'orateur sont imprégnés de l'univers mental féodal : « Il est habituel de donner à son ami de temps à autre un anneau ou une médaille ou autre chose de la sorte, afin que le bénéficiaire conserve le souvenir du donneur » (Ibidem, édition p. 742-743 : «Consuetudo enim est dare amico suo aliquando anulum vel cisum vel aliquid huiusmodi, ut recipiens memoriam habeat conferentis »).

${ }^{85}$ Sur la métaphore comme partie intégrante de l'exégèse littérale au XIII ${ }^{\mathrm{e}}$ siècle, voir en dernier lieu G. Dahan, L'exégèse chrétienne ... op. cit., p. 426-435.
} 
création, mais divise en deux parties ce qui, dans le discours parisien, n'en faisait qu'un et constituait le second point du développement: ici, pour souligner davantage, sur les lieux mêmes où prennent place quelques-uns des grands événements bibliques, notamment 1'Exode du peuple élu de l'Ancien Testament, le parallèle entre 1'Ancienne et la Nouvelle Alliances, l'auteur consacre un premier point aux bienfaits octroyés par le Seigneur à Israël pour éviter que son peuple ne l'oublie, bienfaits dont les principales fêtes juives commémorent, au sens exact, l'institution, et dont les grandes reliques placées dans l'arche d'Alliance, la manne, la verge, les tables et le Deutéronome, rappellent le souvenir ${ }^{86}$; le second point démontre toutefois que tout cela n'est rien en comparaison de ce que le Christ a fait pour les Chrétiens, dont le mémorial culmine sous la forme des saintes reliques, mais qui se traduit aussi dans 1'institution des six grandes fêtes christiques, 1'Annonciation, la Nativité, la Circoncision, le Baptême, la Passion et la Résurrection ${ }^{87}$. Le mélange de notations spirituelles et de comparaisons triviales $^{88}$, caractéristique d'une prédication qui s'adresse largement aux laïcs,

${ }^{86}$ Le parallèle Juifs d'hier - Chrétiens d'aujourd'hui est particulièrement expressif dans le commentaire d'un passage du Deutéronome : «De même, dans le Deutéronome viii, après que le Seigneur a énuméré les bienfaits qu'il a donnés à son peuple en le conduisant hors d'Egypte, en le menant par le désert et en l'introduisant en terre promise, il ajoute... » (suit la citation de Dt. 8, 11-14, qui se termine par une mention de 1'Egypte) ; la traduction ne peut malheureusement rendre la travail de l'auteur sur la langue, son vocabulaire et ses sons (cf. A . Charansonnet, L'université... thèse citée, édition p. 743: "Similiter in Deuteronomio viiio, postquam enumerauit Dominus bona que fecerat populo suo educendo eum de Egipto et deducendo per desertum et inducendo in terram promissionis...»). La même volonté de serrer de près le parallèle entre Ancienne et Nouvelle Alliances, reposant in fine sur les conceptions herméneutiques de l'orateur, se traduit par le fait que le premier point du sermon use exclusivement de citations vétéro-testamentaires, surtout extraites des Livres prophétiques, tandis que le second introduit, commentant la valeur du sacrifice christique, des citations néotestamentaires (par exemple, éd. cit. p. $744:$ «O quomodo gauderet quis si certus esset quod imperator vel rex eum diligeret! Io. Iii ${ }^{\circ}$ : Sic Deus dilexit mundum ut unigenitum suum daret [1o. 3, 16] ; immo Filius seipsum dedit et tradidit semetipsum, redempcionem pro multis. Quod attendens apostolus dicit ad Galatos ultimo : Michi autem absit gloriari nisi in cruce Domini nostri Ihesu Christi » [Gal. 6, 14]). Dans le même ordre d'idées, se situe la mention quasi exhaustive des principales fêtes juives. Sont citées d'une part les trois plus anciennes, qui marquent la rythme des saisons (éd. cit. p; 743 : «Propter hoc, ne ipsi obliuiscerentur beneficia Domini antedicta, instituta fuerunt festa : Pascha, Penthecostes, Cenophegia. Propter hoc etiam reposita fuerunt in archa mahu, virga et tabule et deuteronomius. Et ideo etiam tabernaculum illud tabernaculum testimonii dicebatur... »), à savoir : au printemps, le fêtes des Azymes, très tôt liée avec la solemnité de la Pâque ; en été, la fête de la moisson, dite la fêtes des Semaines ou Pentecôte ; en automne, la fête de la récolte, devenue la fêtes des Huttes (ou, dans les textes grecs, des Tentes, terme rendu en latin par tabernacula). D'autre part, les fêtes plus récentes ne sont pas négligées (éd. cit. p. 743-744: «Sic et in Hester festum Phurim, id est Sortium, fuit institutum, ut Iudei in memoria haberent quomodo Dominus populum suum liberauerat ab excidio quod ei Aman procurauerat. Similiter temporibus Machabeorum festum enciniorum institutum fuit, ut in memoria haberent quomodo Deux eis restituerat templum »): celle des Sorts ou Pourim, et celle de la Dédicace ou Hanoukka. Sur ces fêtes voir A.-M. Gérard, Dictionnaire de la Bible, Paris, 1989 (coll. « Bouquins », éd. R. Laffont), articles «Fête » et «Fête des Huttes », p. 396, «Dédicace (fête de la)», p. 256; G. Wigoder (dir.), Dictionnaire encyclopédique de la Bible, Paris, 1996 (coll. « Bouquins », éd. R. Laffont), article « Fête », p. 365.

${ }^{87} \mathrm{Cf}$. A . Charansonnet, L'université... thèse citée, édition p. $744:$ Hec autem omnia predicta beneficia parua fuerunt immo quasi nulla, in comparacione eorum beneficiorum que Dominus nobis contulit et que pro nobis sustinuit atque gessit. Et ideo ad reuocandum ea ad memoriam instituta sunt festa in Eccleisa Dei : Annunciationis, Natiuitatis, Circumcisionis, Baptismi, Passionis et Resurrectionis, ut nullus possit hec ignorare nec possit se excusare si hoc ignoret ».

${ }^{88}$ Ainsi par exemple : « Nous aimons les chiens car ils nous témoignent des signes d'amitié » (Ibidem, p. 745 : « Diligimus canes quia nobis signa amicitie ostendunt »), constat qui suit de près un paragraphe de haute tenue sur la valeur rédemptrice du sacrifice du Christ : «Qu'est-ce qui doit autant réjouir le cœur de 1'homme, que la 
fournit de nombreux arguments en vue de crédibiliser un objectif essentiel: vous les croisés qui, enivrés et fous de Dieu, avez quitté tout ce qui vous était cher pour suivre le Christ, vous constituez le nouveau peuple élu ${ }^{89}$; d'où l'apostrophe qui suit: " Ainsi le Seigneur a enivré ces temps-ci le roi de France, ses frères, les guerriers et le peuple de ce même royaume pour faire d'eux sa volonté; car s'ils n'avaient point été ivres, ils n'auraient pas pris la croix. Cela, c'est ce mémorial de la Passion du Seigneur qui l'a accompli, semblable au vin, mieux, supérieur au vin du Liban ». Présent aussi ce qui constitue, si l'on peut dire, la marque d'authenticité des sermons d'Eudes de Châteauroux, à savoir l'engagement personnel de l'auteur dans l'entreprise et sa pleine confiance dans la protection divine: il nous livre ainsi le seul passage d'où l'on peut, prudemment, tirer quelques renseignements sur ses origines sociales et culturelles, passage où s'entend une véritable action de grâce à l'intention du créateur, moment d'effusion qui rappelle l'étonnement d'un saint François devant les bienfaits du Christ, ainsi qu'un manifeste clair des fonctions essentielles du prêtre chrétien, la prédication et la sollicitude pastorale pour le troupeau confié à ses soins ${ }^{90}$.

Le troisième sermon aborde les mêmes thèmes dans un contexte encore renouvelé, puisque 1'expédition de croisade, du point de vue de ses objectifs majeurs, a échoué. Ce n'est pas sans amertume que le légat tente alors un bilan explicatif, évidemment indispensable pour convaincre l'armée que le choix de Louis IX de demeurer en Orient est malgré tout justifié.

Ce dernier sermon de la série consacrée par Eudes de Châteauroux à la fête des saintes reliques paraît devoir être daté du 30 septembre 1251 , c'est à dire peu après 1'arrivée en terre sainte, à cause d'une allusion, en tout début du sermon, permise par l'exégèse du verset choisi comme thema du discours. Pour justifier le choix du thema, l'orateur s'appuie en effet sur une citation du Livre de 1'Exode $(16,32)$, où Dieu rappelle aux Israëlites le pain dont il les a nourris dans le désert, lorsqu'il les a fait sortir du pays d'Egypte. Sortir d'Egypte, c'est précisément ce qui vient d'arriver aux croisés ${ }^{91}$. Il y a toutes les raisons de penser, lorsqu'on a

pensée que le Seigneur l'a aimé au point de se sacrifier soi-même pour lui ? » (Ibidem, p. 744 : «Quid ita debet letificare cor hominis, sicut quando recogitat quod Dominus eum tantum dilexit quod seipsum pro eo dedit ? »).

${ }^{89}$ Voir en particulier Ibidem, p. 745, aux lignes 71-87, tout le passage sur le thème de la folie sage, qui sauve les hommes qu'elle paraissait devoir perdre, avec à l'appui de nombreux exemples. Parmi ceux vétérotestamentaires, on en trouve deux, sans doute point par hasard, qui mentionnent des rois, David et Jéhu, ce dernier oint par un disciple d'Hélisée, que les conseillers royaux jugent fou : allusion au choix de Louis IX de débarquer en Egypte, que certains des Grands qui l'accompagnaient auraient critiqué ? L'exemple néotestamentaire mentionne, là encore intentionnellement, la furie du Christ décrite par Marc : implicitement, on retrouve toujours les deux modèles proposés à Louis IX, celui de la royauté biblique et de la royauté du Christ, ainsi qu'une probable allusion à ses décisions stratégiques.

${ }^{90} \mathrm{Cf}$. supra note 79 .

${ }^{91}$ L'allusion à 1 'Egypte, à l'origine de la proposition de datation du sermon, se lit au tout début (Cf. A . Charansonnet, L'université ... thèse citée, édition p. 763): « Hec precepit Dominus Moysi ut esset in memoriale filiis Israel beneficii quod Dominus eis contulerat cibando eos tali cibo, scilicet mahu, et in tali loco, in deserto, 
fréquenté un peu longuement la prédication du cardinal et qu'on connaît ses méthodes d'exégèse biblique, que le thema n'a pas été choisi au hasard et comporte d'abord une signification littérale: nous sommes en Terre sainte, et c'est aux vaincus de la première partie de l'expédition que l'orateur, à l'occasion de cette fête chère, veut redonner espoir, tout en essayant, exercice difficile auquel s'était déjà livré saint Bernard par exemple, d'expliquer les raisons d'une défaite ${ }^{92}$.

Avec ce discours, c'est très probablement la prédication de croisade du légat qui prend fin; il récapitule donc, en les condensant, des thèmes présents dans à peu près tous les sermons antérieurs, et procure un bon résumé de la façon dont, mentalement, des hommes tels Eudes de Châteauroux, Joinville ou Louis IX ont vécu l'expédition. A cet égard, le texte reflète intensément la dévotion, par ailleurs bien documentée, du roi pour la croix et les reliques ${ }^{93}$.

Le premier point du sermon, selon une méthode éprouvée, contextualise le verset thématique choisi dans 1'Exode: «Moïse dit à Aaron: prends un vase, mets-y la manne, un plein gomor, et place-le devant le Seigneur, afin de le préserver pour vos générations » ${ }^{94}$; en remontant un peu en arrière dans le chapitre biblique, jusqu'à la sortie d'Egypte, l'orateur met plus pertinemment en valeur le parallélisme des situations. La trame substantielle du sermon est la suivante: la manne, donnée miraculeusement par Dieu aux Israëlites dans le désert, correspond aux reliques que le Christ a laissées en mémoire de lui; sans doute parce que cette idée a déjà été développée, sous des formes proches, dans le précédent sermon consacré aux reliques, mais plus sûrement parce que les croisés se sont désormais transportés sur les lieux mêmes où vécut le Christ, Eudes de Châteauroux ne prend pas même la peine de justifier cette typologie. Le thème de la commémoration, à travers l'institution de la messe, est très fort chez

et tanto tempore, scilicet quadraginta annis et quousque ipsi gustauerunt fructus terre Chanaan. Unde ibidem preponitur: Iste est sermo quem precepit Dominus : Imple Gomor ex ea et custodiatur in futuras generationes ut nouerint panem quo alui eos in solitudine quando educti estis de terra Egipti $\gg$ (Ex. 16, 32). L'orateur reprend ici, en citant le verset immédiatement antérieur à celui qu'il a choisi pour thème biblique, le parallèle strictement observé dans les deux premiers sermons sur les reliques, montrant que les actions de Dieu en faveur d'Israël préfigurent celles en faveur des Chrétiens dans le Nouveau Testament. On peut proposer une seconde raison, moins convaincante, de privilégier la date de 1251 : des trois sermons qu'on trouve dans les manuscrits, relatifs à la fête des saintes reliques, celui-ci vient en dernier; on peut supposer que cet ordre correspond à celui de la prédication réelle (mais on possède des exemples contraires, où l'ordre dans les manuscrits du cardinal n'est pas celui qu'imposerait la chronologie). Trois dates demeurent possibles : 30 septembre, 1251, 1252 ou 1253 (le roi embarque à Acre pour la France le 25 avril 1254).

${ }_{93}$ Cf. E. Siberry, Criticism of crusading (1095-1274), Oxford, 1985.

${ }^{93} \mathrm{Cf}$. supra note 17 pour le témoignage de Guillaume de Saint-Pathus ; et Ibidem, dans le sixième chapitre, tout le $\S$ intitulé «De sa devocion a la vraie croiz aorer ». Voir aussi les extraits du $\$ 36$ de Geoffroy de Beaulieu (trad. L.-Carolus Barré, Le procès de canonisation de saint Louis (1272-1297). Essai de reconstitution, Rome, 1994), qui débutent ainsi : «En outre, ayant un véritable culte pour la croix, il montrait une telle révérence pour le signe de la sainte croix... ».

${ }^{94}$ Cf. A . Charansonnet, L'université... thèse citée, édition p. 763 : «Dixitque Moyses Aaron : sume vas unum et immite mahu quantum potest capere gomor et repone coram Domino ad seruandum generationes vestras » (Ex. $16,33)$ 
les Chrétiens, puisqu'il évoque les mots mêmes de la consécration eucharistique ${ }^{95}$; significativement, lorsque Guillaume de Saint-Pathus évoque la dévotion du roi pour la croix, il entrelace cette évocation de mentions de son comportement durant la messe, dont cette dévotion est indissociable, juste avant de passer à la dévotion du souverain pour les reliques ${ }^{96}$. De cette façon, le sermon porte autant sur la Passion que sur ce qui conserve sa trace, comme l'énonce clairement le passage suivant: «Ainsi le Seigneur a voulu que ses saintes reliques fussent conservées et non perdues, parmi tant d'adversités qui sont survenues à la Chrétienté, afin que nous nous souvînssions du bienfait que le Seigneur nous a apporté par sa Passion; c'est ainsi que nous le fêtons, pour rappeler par cette fête cet événement à notre mémoire ${ }^{97}$. L'auteur poursuit son propos en esquissant, non plus seulement un rappel des malheurs d'Israël, comme il l'a déjà fait ailleurs - par exemple dans un autre sermon de croisade, pour 1'anniversaire de la mort de Robert d'Artois, 1'aîné des frères du roi, piégé comme on sait lors de la victoire à la Pyrrhus de la Mansourah ${ }^{98}$-, mais une mise en parallèle alternée d'événements vétéro- et néo-testamentaires, série inaugurée par l'évocation de l'institution du sabbat. Il conclut ce premier point en énumérant avec précision, comme dans les deux sermons précédents sur ce thème, les reliques: mais ici, il lie chaque relique au moment précis de la Passion qu'elle rappelle; et revient à son verset thématique, en en confirmant l'exégèse typologique, par 1'interprétation suivante de sa première partie: 1'injonction de Moïse a été adressée à Aaron, ce qui signifie que les prêtres, et tout particulièrement les prélats, le pape, les patriarches et les archevêques, ont une responsabilité particulière dans la commémoration de la Passion; ils doivent avoir « devant les yeux le Seigneur suspendu à la croix » ${ }^{99}$. Il semble qu'on puisse difficilement mieux exprimer le sentiment de l'importance des fonctions pastorales du sacerdoce, plus particulièrement concernant la hiérarchie ecclésiastique.

Le second point met en garde, selon une idée fréquente chez l'auteur, contre la perte de vue spirituelle, intérieure, de la valeur des processions où l'on porte la croix: ce qui compte

\footnotetext{
${ }^{95}$ Voir J.-A. Jungmann, Missarum sollemnia. Explication génétique de la messe romaine, t. I, Paris, 1950, p. 30s. pour le commentaire du récit évangélique, surtout p. 32 pour la commémoration, et passim. R. Cabié, Histoire de la messe des origines à nos jours, Paris, 1990, p. 14s. en particulier, sur la transformation très précoce de l'eucharistie (ce que 1'auteur nomme le passage de la Cène à la Messe, entre le I ${ }^{\text {er }}$ et le III' siècle), marquée par l'apparition de la Mémoire ou Anamnèse, et celle du Récit de l'Institution.

${ }_{97}^{96}$ Cf. supra note 93 .

${ }^{97}$ Cf. A . Charansonnet, L 'université... thèse citée, édition p. 763 : « Sic Dominus voluit ut iste sancte reliquie inter tot aduersa que Christianitati acciderunt seruarentur et non amitterentur, ut memores essemus beneficii quod nobis contulit Dominus in sua Passione. Et ideo etiam festum de hiis agimus, ut per festum hoc ad memoriam reuocemus ». On note ici l'assimilation implicite de la Chrétienté au royaume capétien qui détient ces reliques.

${ }_{98} \mathrm{Cf}$. A . Charansonnet, L'université ... thèse citée, édition du sermon p. 750-756.

99 Ibidem, p. 763 : «Unde et Dominus papa, patriarche et archiespiscopi crucem deferunt ante se ut semper habeant pre oculis Dominum suspensum in cruce ».
} 
n'est pas la pompe que revêtent parfois ces cérémonies, leur ostentation luxueuse, mais le cœur de l'homme qui y participe. Sur la base de cette opposition entre apparence extérieure et vérité intérieure, face à un public sans doute composé en partie de guerriers, Eudes de Châteauroux propose alors un parallèle entre littérature profane et histoire sacrée commémorée par la liturgie: dans la liturgie, le cœur du célébrant comme celui des participants doivent prendre part à la cérémonie; lorsqu'on entend la chanson de Roland, la mort du héros ne touche pas le cœur de celui qui la chante, mais seulement de ceux qui l'écoutent, et encore, parfois seulement ${ }^{100}$. La différence entre le statut, purement interprétatif, du jongleur, et celui qu'on peut nommer «mémorial» ou « réitératif », du célébrant liturgique, n'est pas de trop pour solenniser et sacraliser davantage la cérémonie aux yeux des laïcs. Ces derniers sont ensuite comparés à des rapaces qui oublient l'oiseleur sitôt qu'il les a nourris $^{101}$

Les points suivants du sermon suivent pas à pas les fragments syncopés du thème, selon l'une des méthodes du sermon universitaire dont l'auteur use finalement assez rarement, même s'il la maîtrise parfaitement et l'emploie lorsqu'il l'estime adaptée. Sa théologie témoigne d'un sens humain profond, au cœur des réflexions et expériences chrétiennes de ce siècle ${ }^{102}$ : «Ainsi le cœur de 1'homme fut formé par Dieu à son image et à sa ressemblance, non par quelque artifice ${ }^{103}$. Un peu plus loin, son interprétation de la Passion appuie sur l'écart entre le sort terrestre du Christ aux différents moments de son calvaire, et l'incompréhensible sagesse dont par cet acte il voulut témoigner ${ }^{104}$; non sans noter que, peutêtre à la faveur des événements survenus en Egypte, l'incrédulité a gagné certains rangs chrétiens: «Les sots et les incrédules ont la nausée de ce sacrifice et ne peuvent supporter une telle douceur $\rangle^{105}$.

\footnotetext{
100 Ibidem, p. 764 : «Verecundum etiam est ne ista memoria tota sit de foris, ita quod non tangit cor, sicut tangebat cor illius qui dicebat, Tren . iii $^{\circ}$ : Memoria memor ero et tabescet in me anima mea (Lam. 3, 20). Sicut memoria mortis Rotholandi non tangit cor eius qui de eo cantat, sed tangit aliquando corda eorum qui audiunt ». 101 Ibidem, p. 764 : « Ipsa enim beneficia faciunt eos obliuisci. Succedentibus enim prosperis, obliuiscuntur sui interpretis, Gen. $\mathrm{xl}^{\circ}$ (Gn. 40, 23), sicut ancipiter obliuiscitur eius qui pauit eum et satietas generat in eo hanc obliuionem ».

102 Cf. A. Vauchez, La spiritualité du Moyen age occidental, Paris, $1994^{2}$ (coll. « Points Histoire », éd. Le Seuil), p. 131s.

${ }^{103}$ Cf. A. Charansonnet, L'université... thèse citée, édition p. $765:$ «Sic cor hominis a Deo formatum est ad ymaginem et similitudinem ipsius (Gn. 5, 3), non aliquo artificio ».

104 Ibidem, édition p. 766: "Que maior humilitas quam inter latrones suspendi? Ibi fuit incomprehensibilis sapientia, unde $\mathrm{I}^{\mathrm{a}}$ ad Cor. $\mathrm{i}^{\circ}$ : Quod stultum est Dei, sapientius est omnibus hominibus (1. Cor. 1, 25). In hoc dedit nobis exemplum constantie et patientie ».

105 Ibidem, édition p. 766 : «Sed stulti et increduli nauseant super hoc nec possunt tantam dulcedinem sustinere ».
} 
Des précisions érudites sur la capacité de l'unité de mesure des Hébreux, le gomor, fournissent une ultime métaphore filée sur les deux dernières séquences du verset thématique et aboutissent logiquement à l'idée que la mémoire de la Passion conduira les fidèles de cœur à voir Dieu le Père face à face.

Cette longue méditation sur la Passion, en point d'orgue d'une croisade « ratée », est un indice supplémentaire, si besoin était, de la valeur avant tout religieuse que revêtent, chez Eudes de Châteauroux comme semble-t-il chez les autres prédicateurs ici examinés, la sainte couronne et les autres reliques christiques. Bien sûr, les circonstances politiques et militaires précises qui encadrent ces trois discours ne peuvent être ignorées. Mais tout indique que le roi lui-même partageait cette vision, unissant Passion, reliques et avènement du Royaume. Signe de cette connivence spirituelle, le légat prédicateur a rapporté de Terre sainte de nouvelles reliques christiques dont on lui avait fait présent, et qu'il distribue, en 1257, successivement au sanctuaire de Neuvy-Saint-Sépulcre dans son Berry natal, puis à son frère Hugues, alors trésorier de l'Eglise de Tours et futur évêque de Poitiers ${ }^{106}$; à cela s'ajoute, à la veille de sa mort, le legs aux Dominicains d'Orvieto, chez qui il a choisi de reposer, d'une épine de la couronne du Christ, elle-même don de Louis IX; cette épine accompagne le legs des manuscrits de la seconde édition de ses sermons; 1'association du témoignage de l'humanité du Christ et d'une vie de prédication de sa Parole est hautement significative ${ }^{107}$. Louis IX de la même façon a largement fait profiter ses amis spirituels du trésor de reliques qu'il avait accumulé $^{108}$.

Passé le témoignage très circonstancié d'Eudes de Châteauroux, on retombe dans l'anonymat avec trois sermons contenus dans le second cahier de la série rassemblée par Robert de Sorbon. Il est certain que le premier sermon a été prononcé pour la fête de la Sainte

\footnotetext{
106 Ibidem, volume 1 tome 1, p. 23-24 (note 21) et p. 266-267.

${ }^{107}$ Une note figure en tête du manuscrit de Rome, AGOP XIV, 34, l'un des cinq volumes de sermons légués par le cardinal au couvent fes Frères prêcheurs d'Orvieto, et a d'abord été transcrite par J.-B.Pitra, Analecta novissima spicilegii solesmensis. Altera contimuatio, t. II : Tusculana, Frascati, 1888, p. xxvii, note 1 . Son contenu indique qu'elle n'est pas de la main d'Eudes de Châteauroux., ce que confirme E. Panella, « Autografi di Bartolomeo di Tebaldo da Orvieto », dans Archivum Fratrum Praedicatorum, t. LXII (1992), p. 135-174, qui juge p. 157-158 (note 55) qu'il s'agit d'une écriture de la fin du XIV siècle; il donne une meilleure transcription de la note p. 158, dont voici un extrait : " Nota quod iste venerabilis pater et magister in sacra theologia dedit conuentui urbeuetano unum calicem totum aureum et crucem etiam ex toto de auro $<$ de ?> spina de corona Domini nostri Iesu Christi, quam spinam donauit beatus Ludouicus rex Francie predicto domino cardinali... » (c'est moi qui souligne).

${ }^{108}$ Voir le recensement de ces dons dans C. Billot, «Le message spirituel...», p. 139; outre Eude de Châteauroux, on notera deux récipiendaires particulièrement intéressants pour notre propos : le métropolitain de Tolède en 1248 ; l'évêque de Vicence, le prédicateur domnicain Bartolomeo da Breganza, évoqué sous peu. Sur le culte des reliques christiques au XIII ${ }^{\mathrm{e}}$ siècle, 1'ouvrage cité supra, note 82, de Nicholas Vincent, est désormais indispensable.
} 
Couronne et en présence de celle-ci, et donc très probablement à la Sainte-Chapelle ${ }^{109}$. Rien ne permet cependant d'affirmer qu'il a été donné devant le roi ni d'ailleurs qu'il a été prononcé avant 1270. Le sermon, rédigé dans un style plutôt recherché et nettement plus long que tous les autres, a pour thema le verset 25 du Psaume 135 (Qui dat escam omni carni), un verset très rarement choisi par les prédicateurs, à tel point que parmi les quelques dizaines de milliers de sermons du répertoire de J.-B. Schneyer, il est le seul à proposer ce verset thématique.

Après avoir rappelé dans le prothème la nécessité de méditer attentivement sur chacune des étapes de la Passion, le prédicateur anonyme explique qu'il ne faut pas s'étonner du caractère joyeux de fête de la Couronne, car si la Parascève est un jour de tristesse pendant lequel il faut remémorer les souffrances du Christ, la fête du mois d'août est celle qui doit célébrer la récolte abondante née des saintes épines ${ }^{110}$. Le sermon développe par la suite un enseignement assez savant qui traite des quatre couronnes qui ont été ou seront portées par le Christ : la couronne de 1'humanité, celle de la Passion, de la justice et de la gloire.

C'est bien sûr dans le ventre de la Vierge que le Christ a reçu la couronne de l'Incarnation : en choisissant comme ornement la chair humaine, Dieu a voulu parer ce qui n'a aucune valeur par ce qui est précieux, ce qui est humble par ce qui est excellent, ce qui est transitoire par ce qui est éternel, et accomplir ainsi son plus grand miracle, car 'c'est un plus grand miracle d'avoir triomphé dans la chair fragile de toutes les iniquités spirituelles que d'avoir créé le ciel et la terre' ${ }^{111}$.

Dans le long passage consacré à la couronne de la Passion, le sermon développe d'abord quelques réflexions à caractère ecclésiologique pour ensuite mentionner quelques-uns des devoirs des rois. Le sermon explique ainsi que de la tête couronnée d'épines du Christ est sorti le baume qui doit descendre à travers la barbe d'Aaron jusqu'à l'extrémité du vêtement, c'est-

\footnotetext{
109 « Preciosa sit et graciosa nobis hec corona, licet fuerit spinosa, quia spine iste saluti nostre sunt fructuose et sterilis non est in eis » (ibid. f. 123rb).

110 « Non miretur ergo uel indignetur ortodoxorum quispiam si iocunda corone dominice sollempnitatis paucos dies nunc expendat in laudibus redemptoris. Quia etsi hec corona capiti saluatoris ad penam et ludibrium in die parasceues fuerit applicata, tamen, quia dies illa non est gaudii sed meroris, quando membra compatiuntur capiti et musica in luctu sit importuna, narratio differtur interim hec gratulabunda festiuitas, in qua recolligimus salutis nostre messem de spinarum semine propagatam. Illa die meroris euntes ibant fideles et flebant quando salutis sue semina metebantur, uenientes autem nunc ueniunt cum exultatione portantes manipulos uite sue... » (ibid. $\mathrm{f}$. 123rb-va). Un peu plus loin, le sermon souligne l'importance du mois d'août: «Pulchre autem in augusto sanctarum spinarum iocundam messem recolligimus, quando quasi in augusto speciali sacre benedictionis augmentum ex copiosis diuine largitatis beneficiis confidentius expectamus... » (ibid., f. 123va).

${ }_{111}$ "Quomodo dicimus Deum carne adornari preciosum uili, excellentem humili, eternum temporali ? Sed ideo caro humana potest dici ornamentum Dei, quia Deus in ea maius miraculum fecit quam per se prius fecerat. Maius est enim in carne fragili omnes spirituales nequicias triumphasse, quam celum et terram fabricasse. Miranda magis uictoria est per carnem omni miserie naturaliter obnoxiam hominem redemisse, quam Deum quicquid uult potentem hominem plasmauisse » (ibid. f. 123vb-124ra).
} 
à-dire la grâce qui doit se répandre par le biais du sermon des prédicateurs jusqu'aux extrémités de l'Église ${ }^{112}$. Reprenant l'idée augustinienne que la tête est le siège de tous les sens et que c'est dans le sommet de la tête que réside celui qui doit présider à la monarchie de tout le corps, à savoir le tact, il explique que c'est pour ce motif que le diadème est également le signe de la dignité royale ${ }^{113}$. La forme circulaire de la couronne doit rappeler à ceux qui régissent les autres qu'ils doivent exercer leur fonction avec circonspection, constat qui fournit l'occasion de rappeler que les rois doivent exercer la justice en se faisant assister par la sagesse et la miséricorde, qu'ils ne doivent jamais agir de manière précipitée et toujours faire l'effort de prévoir ce qui est utile et équilibré ; qu'ils ne doivent jamais s'enorgueillir et dévier $\mathrm{du}$ chemin du droit pour faire une faveur aux amis ou par amour pour quelque chose de familier, et enfin qu'ils ne doivent jamais quitter la voie du Seigneur en succombant à la colère, en recherchant la vindicte ou en privant les ennemis de justice ${ }^{114}$.

Dans une longue digression, le prédicateur anonyme évoque également la Passion et plus précisément le rôle de la Couronne d'épines utilisée à la fois pour dérider le Christ, mais sans que la tête du Sauveur souffre, et pour indiquer à ceux qui ne pouvaient pas lire la raison de la crucifixion $^{115}$. Objet sans aucune valeur, que même les soldats n'ont voulu se partager, la Couronne a par la suite acquis une valeur inestimable grâce à la volonté divine ${ }^{116}$.

\footnotetext{
112 «Pios igitur huiusmodi corone aspiciamus apices, medicum nostrum propter necessitatem honorantes; unguentum in capite descendat in barbam, id est barbam Aaron, et inde descendat in oram uestimenti eius. Vnguentum medicinalis misericordie descendat a capite Thesu spinis pro nobis coronati in barbam, hoc est in sermonem predicantium fortiter et laudantium, quo mentes audientium purgantur et compurgantur. Et sic ad extremos ecclesie descendat unguentum gratie saluatoris » (ibid. f. 124ra-rb).

113 « In uertice enim capitis solus tactus uiget, qui in omnibus sensibus quasi rex principatur. Vnde, cum totius corporis monarchie presideat princeps omnium sensuum loco et potestate sublimior, dignitatis regie signum non indigne possidet dyadema. Ideo etiam congrue corona cultus est capitis, eo quod in capite est domestica camera sensuum et cellule rationis, operationibus inuentioni, discretioni et memorie deputate » (ibid., f. 124va).

114 « Nec uacat a misterio quod figura corone capite regis circulariter circumcingit, ut qui regulariter uult preesse et prodesse pro se et pro suis, cautus sit et in omnibus circonspectus [...] Retro sit corona, ne qui preest retro cadat, sed posteriorum oblitus ad anteriora se extendat. Retro sit corona ut qui mittit manum ad aratrum, retro non aspiciat ne regno Dei ineptus fiat. Ante sit corona, ne nimis sit iniustus, sed iusticie sue sapientiam et misericordiam habeat assistrices. Ante sit corona, ne in preceps ruat, sed studeat moderata et utilia in posterum prouidere. A dextris sit corona, ne in elationem animi uirtutes eum et successus prosperitatis ad uanitatem extolant. A dextris sit corona, ne amicorum fauore uel rei familiaris amore a iuris tramite ad iniurie deuia se flectat. A sinistris sit corona, ne delinquendo uiam Domini derelinquat, ne per iram ultionem querat, ne inimicis suis iniuste differat uel auferat iusticie complementum » (ibid. f. 124va-vb).

115 « Licet autem inter preludia passionis dominicie ab illudentibus ad ludibrium et punctionum aculeum fuerit imposita capiti innocenti spinea corona, pie tamen et sobrie credi potest in ipso crucifixionis articulo eam minime defuisse, et pendente corpore et membris confossis solum caput a pena tunc uacuum exstitisse » (ibid. f. $124 \mathrm{vb})$; «Pretenderant enim Iudei causam crucifixionis Christi quod se regem faciebat, dicentes Pilato : si hunc dimittis non es amicus Cesaris. Omnis enim qui se regem facit contradicit Cesari. Propter hoc imposuerunt super caput eius causam ipsius scriptam : hic est Ihesus nazarenus rex Iudeorum. Forsitan intentione simili signum cause mortis eius coronam capiti impositam, omnibus etiam litteras nescientibus ostendebant » (ibid. f. 125ra).

116 «Hinc est quod contumelia crucis et spinei dyademati uersa sunt in decus sacramenti. Merito itaque omnipotens nominatur, ad cuius nutum omnis res ita permutatur. Mirabilis igitur omnium artifex sapientia noua et inaudite inuentrix alquimie, non de argento aurum mutatis substantiis faciendo, sed super aurum ditando spinas inimicorum in suas species remanentes. Sic enim ignobilia et contemtibilia elegit Deus et ea que non sunt,
} 
La fin du sermon est consacrée à la couronne de justice et à celle de gloire. Elle propose une réflexion assez compliquée qui vise en quelque sorte à mettre en évidence le caractère à la fois éternel et historique de ces deux couronnes, en distinguant par exemple trois couronnes de gloire: celle de la gloire éternelle des trois personnes de la Trinité qui est là depuis toujours, celle de la double nature du Christ et enfin celle que le Christ possédera pleinement après le Jugement lorsqu'il sera au milieu des élus. Les quatre couronnes 'principales' sont à nouveau présentées dans la conclusion par le biais de l'explication de ce que le prédicateur appelle la 'prophétie mystique' de Zacharie 6,14, verset qui évoque la couronne qui devait servir de mémorial dans le Temple du Seigneur, et qui permet donc aussi, tout au moins implicitement, de rappeler la présence physique de la Couronne d'épines.

Ce très long sermon anonyme paraît avoir été prévu pour une assistance cultivée, capable de suivre le parcours somme toute plutôt compliqué proposé par le prédicateur et de saisir le jeu subtil des correspondances établies entre les différentes couronnes mentionnées par le texte biblique, tout comme de comprendre l'idée de fond du sermon qui est celle de montrer comment la Couronne d'épines participe à des temporalités différentes et représente une invitation qui s'adresse à tout chrétien pour l'encourager à tout mettre en œuvre pour mériter celle qui sera donnée aux élus. Dans cette perspective, au-delà des réflexions sur les devoirs du roi, le sermon est avant tout une exhortation à la pénitence et au combat contre le péché.

L'avant dernier sermon est le seul qui consacre un développement au thème de la royauté du Christ ou, plus précisément, explique de manière assez détaillée les trois caractéristiques qui rendent celle-ci incomparablement supérieure à la royauté terrestre ${ }^{117}$. Cette supériorité est manifeste tout d'abord du point de vue de la majesté du royaume : alors que les autres rois sont particuliers, le Christ est le roi universel ; elle est également supérieure parce que ce roi est le seul à pouvoir instituer les autres rois : c'est en effet le Christ qui a institué les rois et leur a conféré un certain nombre de droits ; lorsque les rois agissent de manière injuste, par exemple en opprimant les pauvres ou en profitant de leur fonction pour promouvoir au sein de l'Église leurs proches ignorants à la place des clercs bons et cultivés, ils ne règnent cependant plus avec l'approbation du Christ mais uniquement avec sa permission. Enfin, la royauté du Christ est supérieure du point de vue de la puissance, car les rois, même s'ils vivent longtemps, finissent toujours par devoir abandonner leur royaume quand ils meurent: par

ut ea que sunt destrueret et iuncorum paupertas inestimabili precio uinceret aurum, argentum et lapidem preciosum » (ibid. , f. 125rb).

117 «Primo ergo notatur regalis dignitas cum dicit regem. Iste est rex ad presens et excellit alios reges in tribus. Primo in excellentia maiestatis regie. Secundo in aliorum regum institutione. Tercio in ipsius regni inexterminata potestate » (ibid., f. 128rb). Sur la royauté du Christ le travail essentiel demeure celui de J. Leclercq, L'idée de la royauté du Christ au moyen Âge, Paris, 1959. 
conséquent, précise le sermon, ils sont comme les rois de la fève qui ne règnent qu'un court moment. De plus, même les rois les plus puissants, comme par exemple Alexandre le Grand, ne peuvent transmettre à leurs enfants qu'une partie de leur royaume, alors que le Christ donne à chacun $1^{\prime}$ intégralité du $\operatorname{sien}^{118}$. En opposant systématiquement un roi à des rois, le singulier au pluriel, le sermon développe une réflexion qui vise à mettre en évidence surtout ce qui différencie les deux types de royauté et à rappeler que celle qui est exercée sur terre par des hommes n'a en définitive pas grand-chose de comparable avec la royauté du Christ.

Quant au dernier sermon, peut-être de Robert de Sorbon ${ }^{119}$, il développe l'idée que la fête de la Couronne est une invitation à méditer la passion du Christ et les deux formes de douleur qu'il a supportées $^{120}$. Assez habilement, le prédicateur distingue entre la douleur physique du Christ causée par les péchés charnels - à laquelle il faut penser surtout pendant la période de Carême - et la douleur intérieure provoquée par les péchés spirituels, sujet de réflexion auquel incite plus spécifiquement la fête du mois d'août ${ }^{121}$.

L'échantillon offert par la collection de Robert de Sorbon permet avant tout de constater que les thèmes abordés par les prédicateurs lors des deux fêtes consacrées aux reliques de la Passion étaient somme toute assez variés. À l'exception tout à fait notable d'Eudes de Châteauroux, les clercs qui ont pris la parole à la Sainte-Chapelle ou ailleurs ne semblent cependant pas avoir fait preuve d'une très grande originalité. Leur discours reste pour l'essentiel centré autour de la Passion et de la nécessité de la pénitence et, comme nous

\footnotetext{
118 « Alii reges sunt particulares, iste uniuersalis, quia rex omnium regum et regnorum [...]. Item excellit in aliorum regum institutione. Vnde ipse instituit et reges et iura ipsorum, Prou. VIII : per me reges regnant et legum conditores iura decreuunt et cet. Cum iniquas leges condunt non est a Deo sed a se ipsis [...], Ysaie X : ue qui condunt leges iniquas ut opprimant in iudicio pauperes, sicut qui illos opprimunt quibus posset esse profectus in ecclesia Dei ut bonas et litteratas personas et suos ignorantes cognatos promouent et etiam qui eis aliquando in officio seruierunt. De talibus dicit Dominus per prophetam : ipsi (ipse cod.) regnauerunt, sed non ex me, scilicet approbante, sed ex me permittente. Item excellit in exterminata regni potestate. Alii reges etsi aliquamdiu uiuant tandem dimittunt regnum per mortem. Sed potestas eius potestas eterna, et regni eius non erit finis [...]. Alii reges sunt reges fabe qui regnant per breuem horam. Eccli. IX : rex est hodie et cras morietur. Item reges terreni dant parua dona, quia aliquando partem regni, sicut legitur in libro Mathei I de Alexandro magno rege, cum deberet mori, dimisit pueris scilicet regnum illum, et cet. Sed rex noster cuilibet dat totum regnum suum $[\ldots]$ » (ibid. $128 \mathrm{rb}$-va).

119 Pour chaque occasion liturgique, les copistes des recueils ont utilisé un ou plusieurs cahiers. Assez souvent, quelques sermons de Robert de Sorbon, toujours anonymes, ont été copiés à la fin du dernier cahier utilisé. L'attribution de celui-ci à Robert de Sorbon, très hypothétique, est suggérée à la suite d'une citation attribuée explicitement à Guiart de Laon que Robert de Sorbon tenait comme un des meilleurs prédicateurs de son temps ( Et dicitur ibi in Euuangelio quod assumpsit Christus Ihesus discipulos suos secreto, id est ad priuatum et secretum consilium. Sic exponit dominus Guiardus Camerancensis » (ibid. f. 129vb).

${ }^{120}$ «Nunc est tempus flendi et non ridendi, compatiendo scilicet saluatori nostro hodie pro nobis passo. Et tempus loquendi, non tacendi, ad exhortandos nos muto ad compassionem et fletum » (ibid., f. 129ra).

121 «Et propter hunc duplicem dolorem eius, bis in anno fit mencio de eius passione, scilicet nunc et dominica tertia in quadragesima. Nunc pro dolore interiori, tunc pro exteriori, eo quod illis tribus diebus plus solito multiplicantur cause illius doloris per gulam, per luxuriam [...] » (ibid., f. 129vb).
} 
l'avons vu, les allusions au thème du pouvoir royal visent avant tout à souligner la condition inexorablement humaine de la souveraineté terrestre.

Ce constat est confirmé par les deux ${ }^{122}$ sermons donnés à la Sainte-Chapelle en 1272-73 conservés par le recueil de Pierre de Limoges qui vient d'être magistralement étudié par Nicole Bériou ${ }^{123}$. Le premier a été prononcé pour 1'anniversaire de la Dédicace de la SainteChapelle par Jean d'Orléans, chancelier de l'université. Le deuxième par Jean de Samois, gardien du couvent des franciscains, pour la fête des reliques.

Jean d'Orléans, qui a choisi comme verset thématique le passage du deuxième livre des Chroniques qui décrit la Dédicace du Temple par Salomon et son peuple, constate d'emblée que ce passage peut aussi s'appliquer à Louis IX et à son peuple ${ }^{124}$, mais développe par la suite son sermon autour de l'idée que chacun doit être le roi et l'évêque de son propre temple, thème courant dans les sermons pour la Dédicace ${ }^{125}$. Quant à Jean de Samois, dans un sermon qui s'ouvre par le rappel des souffrances infligées au Christ et développe par la suite, assez subtilement, un enseignement à caractère moral destiné aux puissants, il fait référence au vitrail de la Passion pour expliquer l'idée que chaque péché commis par un chrétien blesse à nouveau le Christ, idée, dit-i1, qui est confirmée ad litteram par Zacharie 13,6 (« J’ai reçu ces blessures dans la maison de ceux qui m'aimaient »), mais qui, ajoute-t-il, dans cette chapelle peut être confirmée par la vue ${ }^{126}$. Il souligne plus loin que les saintes reliques ont toujours été auprès des savants, d'abord en Grèce, où le clergé était autrefois florissant, et maintenant à Paris, où se trouve, dit-i1, la source de toute la sagesse ${ }^{127}$. Si Jean de Samois s'empresse de bénir l'action de celui qui a fait venir les reliques et les a installées aussi honorablement bénédiction qu'il élargit à celui qui poursuivra ce qui a été commencé, allusion à Philippe III qui est présent au sermon - il n'insiste guère sur cet aspect ${ }^{128}$.

\footnotetext{
${ }^{122}$ Nous laissons de côté un troisième sermon, donné par le dominicain Jean de Troyes pour la fête de la Sainte Couronne en présence du roi et de l'archevêque Eudes Rigaud qui n'a été conservé que de manière fragmentaire. Le sermon développe le thème des cinq couronnes qui ont été portées par le Seigneur (Paris, BnF lat. 16482, f. $17 \mathrm{va}-\mathrm{vb}$ et $130 \mathrm{vb})$.

123 L'avènement des maîtres de la Parole. La prédication à Paris au XIII é siècle, Paris, 2 vol., 1998.

124 «[Dedicatio]. Cancellarius parisiensis in capella regis. Dedicauerunt templum Domini rex et filii Israel. Quod dicitur de rege Salomone et filiis Israel potest dici de rege Francie bone memorie et de populo » (ibid., f. 28ra). Un prédicateur anonyme évoque l'accueil festif que Saint Louis a réservé à la Sainte Croix (cf. N. Bériou, L'avènement des maîtres..., t. 1, p. 301, n. 53).

125 « Rex et episcopus debet esse quilibet nostrum se dedicans Deo. Quilibet enim uir et similiter mulier habet non modicum regnum regere, scilicet corpus et animam, que ualde periculosa sunt ad regendum » (ibid. f. 28ra).

126 «Hiis ergo plagatus, et cet. Hiis est demonstratiuum ad litteram hic, sed in hac capella potest esse demonstratiuum ad oculum » (ibid. f. 131va).

127 «Vnde semper fuerunt iste reliquie apud sapientes. Primo in Grecia, ubi uigebat tunc clerus, nunc autem Parisius, ubi est fons totius sapientie » (ibid. f. 131va).

128 « Benedictus qui istas [reliquias] apportauit et tam honorifice collocauit, et qui continuabit inchoatum » (ibid. f. 131va-vb). Le reste du sermon propose une longue description des blessures infligées par le péché au corps
} 
C'est paradoxalement dans les sermons pour la fête de la Couronne d'épines prononcés en Italie, et plus précisément à Vicence, que la famille royale et Paris font l'objet de remarques qui mettent davantage en évidence leur rôle. Évêque de Limassol et plus tard de Vicence, en 1259 le dominicain Barthélemy de Breganze a reçu à Paris de Louis IX, à côté de qui il avait séjourné en Palestine, une des épines de la Sainte Couronne et un morceau de la Vraie Croix, qu'il avait ramenés en Italie en passant le col du Simplon enneigé. En 1260, Barthélemy avait remis les reliques à l'église de la Sacra Corona du couvent des dominicains de Vicence. Trois des sermons qu'il a donnés pour la fête de la Couronne entre 1264 et 1270 ont été conservés $^{129}$. Ils permettent de constater que l'évêque de Vicence n'hésitait pas, quand il prêchait sur la Couronne, à magnifier le roi de France et sa mère. Ainsi, pour n'évoquer qu'un seul exemple, dans un sermon il compare ouvertement Blanche de Castille à Hélène, à qui on doit l'invention de la Croix de Victoire, et son père Constantin, qualifié de conservateur des saintes reliques, au très dévot roi Louis, tout en soulignant que si la couronne avait été transférée dans un premier temps de Jérusalem à Byzance, elle avait dû par la suite quitter cette ville à cause de la perfidie de celle-ci, et que désormais c'était Paris qu'elle couronnait de gloire et d'honneur ${ }^{130}$.

Quelques remarques en guise de conclusion. Si l'on juge d'après les sermons qui ont été conservés par les recueils de Robert de Sorbon et de Pierre de Limoges, il semble bien que les prédicateurs qui ont pris la parole lors de la fête de la Couronne et des Saintes Reliques ont abordé assez rarement le thème de la royauté. Lorsqu'ils l'ont fait, ce n'était certainement pas pour amener leur contribution à l'élaboration d'une idéologie au service de la glorification du pouvoir royal ou de la personne du roi, mais plutôt pour rappeler le caractère transitoire et limité du pouvoir des rois et pour exprimer, comme l'écrit Nicole Bériou à propos des sermons donnés devant le roi, 'une conception de la royauté ministérielle, et subordonnée à celle du Christ ${ }^{131}$. Les thèmes présents dans les deux relations de la translation, tout comme celui suggéré en 1244 par Innocent IV du Christ qui aurait lui-même couronné Saint Louis, ne semblent guère avoir inspiré nos prédicateurs. Certes, ce constat repose sur un nombre limité

social qui est, comme l'écrit N. Bériou, « au service d'une mise en garde à l'adresse des hommes de pouvoir » (L'avènement des maîtres..., t. 1, p. 344).

129 L'ensemble du dossier a été publié et étudié par F. Lomastro Tognato, I "Monumenta reliquiamum » $S$. Corona di Vicenza, Padova, 1992. Les trois sermons sur la Couronne d'épines de l'évêque de Vicence ont été édités aux pages 149-156.

${ }^{130}$ Ibid. p. 153.

131 L'avènement des maîtres..., t. 1, p. 311. Sur ces aspects cf. J. Krynen, L'empire du roi. Idées et croyances politiques en France, XIII $I^{e}-X I V^{e}$ siècles, Paris, 1993. 
de sermons qui datent tous d'avant $1273-74$, et il est possible que le recours à des textes d'autre nature ${ }^{132}$ ou l'examen des sermons prononcés à d'autres occasions - notamment les sermons donnés pour l'Exaltation de la Croix (14 septembre) - ou postérieurs aux limites chronologiques que nous nous sommes fixées, permettrait de repérer des attitudes différentes. On peut néanmoins noter que Boniface VIII, dans le deuxième sermon sur la canonisation de Saint Louis qu'il a prononcé à Orvieto le 11 août 1297, le jour donc où à Paris on fêtait la susception de la Couronne, ne fait aucune allusion à celle-ci ${ }^{133}$.

Le témoignage d'Eudes de Châteauroux, sans doute le plus 'engagé' politiquement de tous les orateurs ici évoqués, incite lui aussi à nuancer les interprétations trop schématiques des historiens de la Sainte-Chapelle concernant les reliques du Christ, qui concluent un peu vite à l'exaltation sans frein de la royauté élue des Capétiens. C'est oublier qu'un conseil clérical éclaire le Prince et que l'exégèse chrétienne traditionnelle, si attachée qu'elle soit à la lettre de l'Écriture, en vise 1'Esprit. En ce sens, la seule vraie royauté dont les reliques léguées par le Sauveur à son peuple puissent témoigner, c'est de la Sienne, Eudes de Châteauroux s'emploie quelques années plus tard à le démontrer contre le frère de Louis IX, Charles d'Anjou. Au plan théologique, à l'issue du Jugement dernier, tous les bons chrétiens seront rois avec et dans le Christ vu «facie ad faciem », c'est l'une des doxologies préférées du cardinal. I1 revient dans ce cadre au souverain temporel de montrer l'exemple, ce que le futur saint Louis a fait avec brio. Les combattants de la Septième croisade, à défaut d'entendre un programme de propagande capétienne, ont écouté un guide spirituel, s'adressant d'abord à leur foi, pour la conforter dans la gloire comme l'adversité. Si le message présente moins d'originalité qu'on ne le voudrait, il confirme sur un point la spécificité profonde du Christianisme médiéval : les deux pouvoirs, le spirituel et le temporel, s'y exposent d'emblée et très longtemps à la fois comme distincts et indissociables.

C'est surtout dès le XIV siècle qu'on trouve un certain nombre de textes qui utilisent amplement le thème de la présence des reliques à Paris pour souligner la supériorité de la royauté française. C'est le cas, par exemple, du discours construit comme un véritable sermon prononcé peut-être en 1365 par le conseiller de Charles V Anseau Choquart devant le pape Urbain $\mathrm{V}$, discours qui avait pour objectif de convaincre le pape à ne pas quitter Avignon pour rentrer à Rome. Anseau Choquart insiste sur l'idée que les reliques sont en France par la volonté de Dieu, que désormais la sainteté de la France est plus grande que celle de la Terre

\footnotetext{
${ }^{132}$ Voir par exemple le passage de la Chronique anonyme des rois de France finissant en l'an 1286 cité par Cl. Billot, « Le message spirituel... », p. 138.

${ }^{133}$ Le sermon a été publié dans $R H F$, t. 23, p. 152-153.
} 
Sainte et que les reliques de la Sainte-Chapelle sont bien plus précieuses que celles qui étaient conservées dans l'arche, ce qui l'amène à observer que saint Louis, par l'engagement dont il a fait preuve pour obtenir les reliques, a acquis la dignité du premier ordre et ses successeurs le titre de gardiens spirituels des saintes reliques, reliques qu'ils ont été chargés par le Seigneur de conserver jusqu'au jour du Jugement dernier ${ }^{134}$. Le thème de la translatio reliquiarum est par ailleurs associé à celui de la translatio studii ${ }^{135}$, mais contrairement à Jean de Samois qui n'avait que suggéré de manière rapide cette association, Anseau Choquart y consacre un long développement, afin bien entendu de prouver la supériorité de Paris sur Rome et l'élection des rois de France et de leur peuple.

\author{
Alexis CHARANSONNET (Université de Lyon 2) \\ Franco MORENZONI (Université de Genève)
}

\footnotetext{
134 « Et uerisimiliter credendum est, quod eedem reliquie sancte que adesse uerisimiliter creduntur in die iudicii, [...] ab ipso saluatore et angelis eisdem assistentibus continuo conseruentur, et quod eisdem assistat diuina presentia cum multiplici angelorum comitiua, quasi precipuus Domini thesaurus in terris, cuius thesauri Christus cum suis angelis spiritualibus [...] et filius uester christianissimus rex Francie custos existit spiritualis [...]. Ipse est enim qui contemplatione meritorum in prouincias maritimas strenuissimo milite pro fide et hiis sanctissimis reliquis obtinendis primi ordinis dignitatem fuit consecutus; ideoque altissimarum dignitatum honoribus subiungatur [...]. Rex iste et suus populus prepositi signo et uexillo pretiosissimo imperatoris nostri, scilicet saluatoris nostri, qui per hoc signum triumphauit diuino iudicio, ad idem sunt promoti ; ideoque inter electos, id est inter alios principes et populos a Christo electos, clarissimi sunt et ampliori prerogatiua digni, quos diuini lateris, id est signorum diuinorum comitatus illustrat » (Paris, BnF lat. 14644, f. 6v). L'édition de C.-E. Du Boulay (Historia universitatis parisiensis, Paris, 1665-1673, t. 4, p. 396-412) est très fautive. Une nouvelle édition de ce texte est en préparation.

${ }^{135}$ Sur cet aspect, cf. C. Beaune, Naissance de la nation France, Paris, 1985, p. 300-303.
} 